\title{
THE IMPACT OF PRACTICEING HUMAN RELATIONS BY ISLAMIC EDUCATION TEACHERS ON THE 11TH GRADE STUDENTS' ATTITUDES TOWARDS THE SUBJECT IN THE SULTANATE OF OMAN

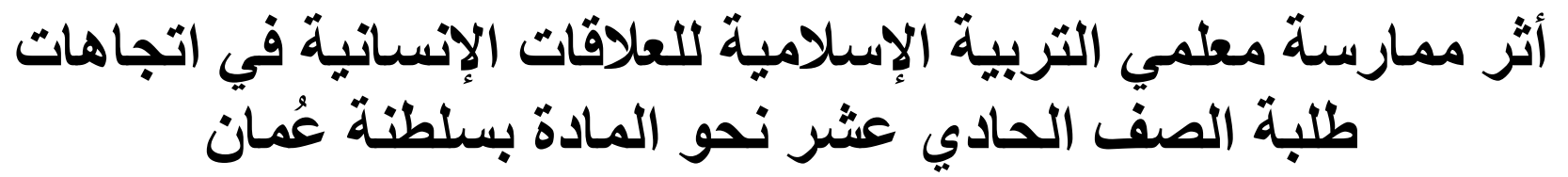

$$
\text { عبدالله بن سيف بن زهران الرمحي }
$$

\section{Abdullah Saif Zahran Al Rumhi ${ }^{1^{*}}$, Mastura Badzis ${ }^{2}$, Hashil Saad Suroor Alghafri ${ }^{3}$}

${ }^{1} \mathrm{Ph} . \mathrm{D}$. Candidate at the Faculty of Education, International Islamic University Malaysia (IIUM); abd.rumhi@moe.om

${ }^{2}$ Senior Lecturer Dr. at the Faculty of Education, International Islamic University Malaysia, bmastura@iium.edu.my

${ }^{3}$ Assoc. Prof. Dr. at AIRustaq College Education Sultanate of Oman, dhashil@hotmail.com ${ }^{*}$ Corresponding Author

\begin{abstract}
This study aims to investigate the relationship between Islamic education teachers' practices of humanitarian relations and (Male and Female) and grade 11 student's attitudes towards the subject in the Sultanate of Oman. The study population is all grade 11 male and female students in the public schools in South Batinah, which are (8592) students. And the sample was (383) students, according to Gracie and Morgan's (1970) table. To achieve the study goals, the researcher uses the correlative methodology, designed a questionnaire consisting of (30) statements distributed in six axes., and another questionnaire of (20) statements that used for the attitude measurement. The study findings showed that the Islamic education teachers' humanitarian practices in the educational learning process were high (4.09) and that the students' attitudes were high. The study recommends the necessity of employing human relations in attracting and suspending students towards the educational material and towards the teacher, and positively changing their attitudes towards the Islamic education subject.
\end{abstract}

Keywords: Islamic education, human relations, student attitudes.

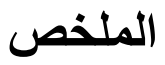

هدفت هذه الدر اسـة الكميـة، إلى الكثنف عن حجم العلاقة بين ممارسـة معلمي التربيـة الإسـلامية

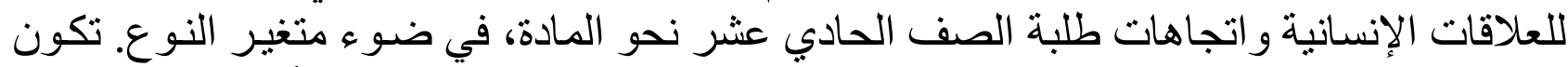

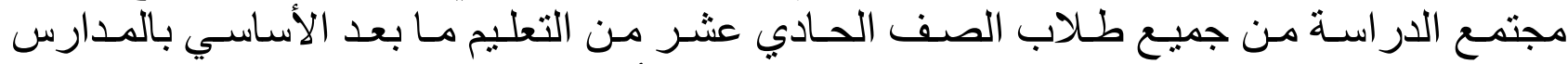

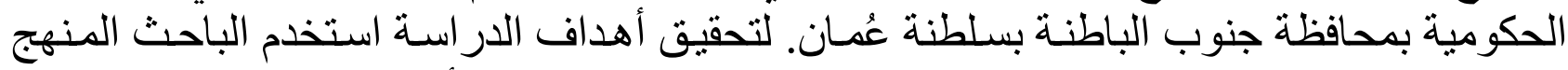

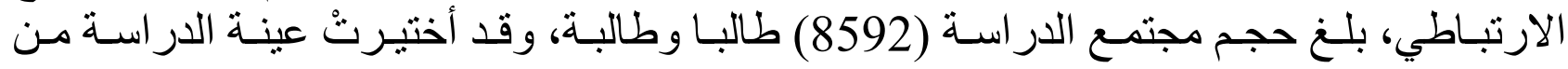


(383) طالباً وطالبة، حسب جدول جريسي ومور غان (1970). أعد الباحث استبانة وفق المقباس

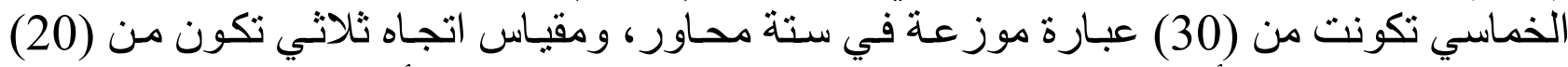

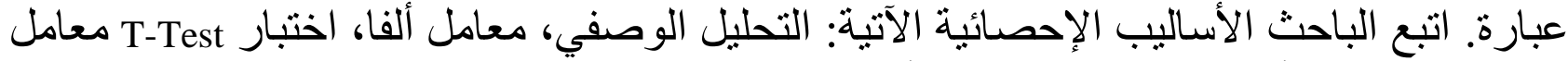

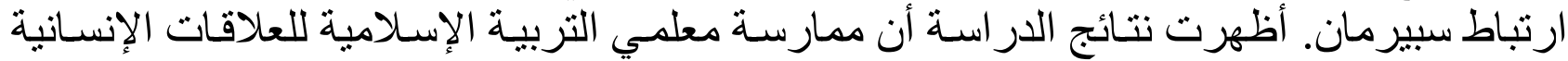

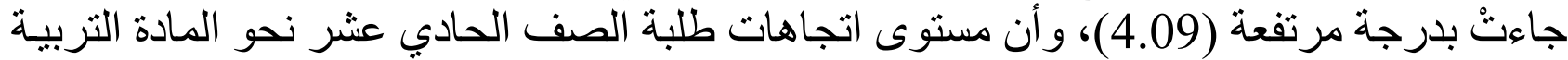

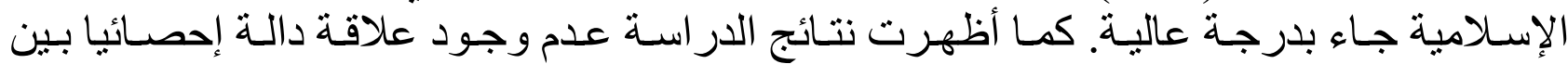

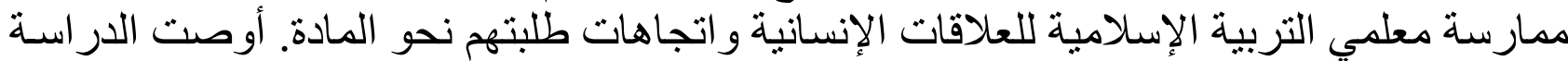

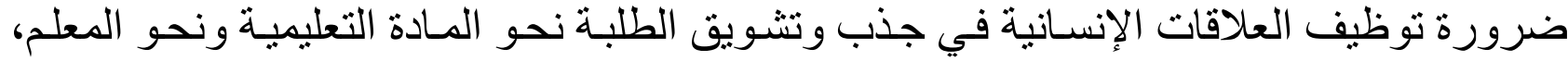
وتغيير اتجاهاتهم بشكل إيجابي نحو مادة التربية الإسلامية.

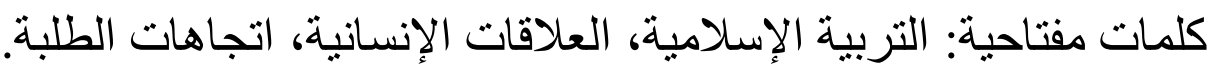

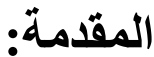

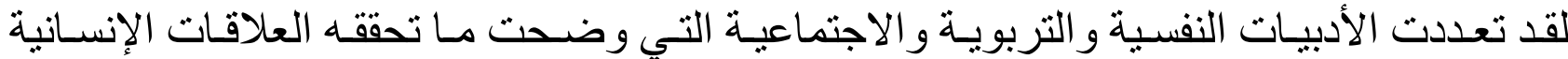

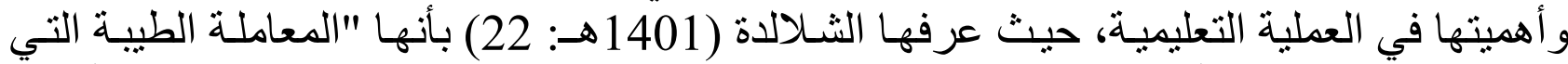

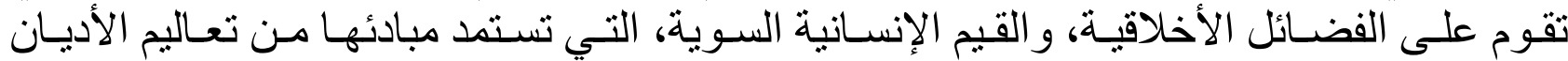

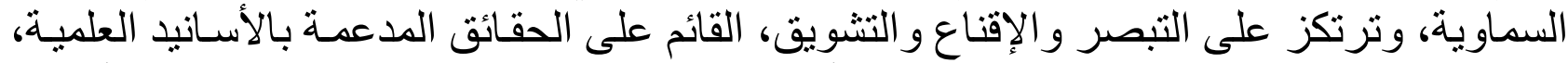

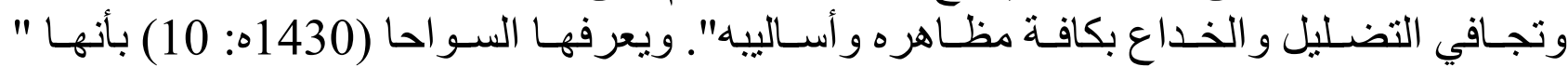

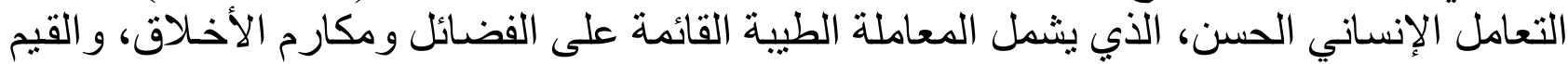

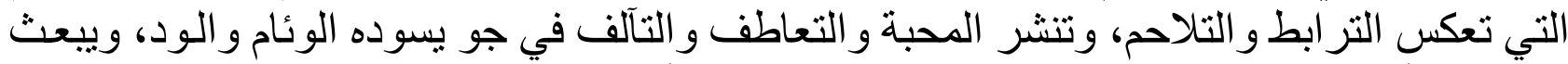

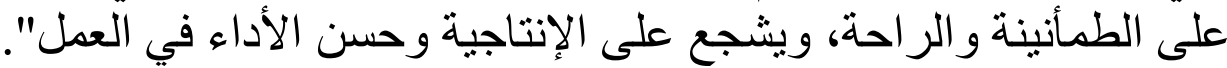

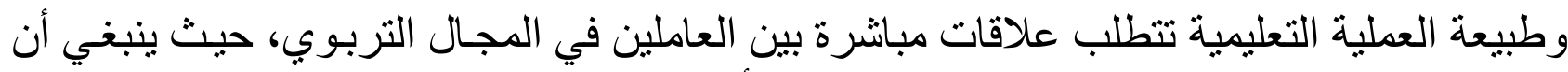

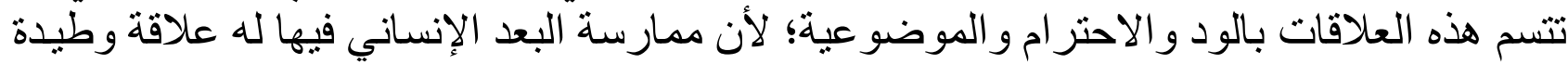

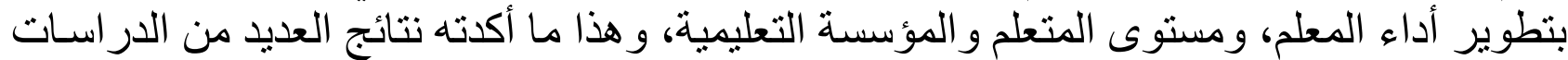

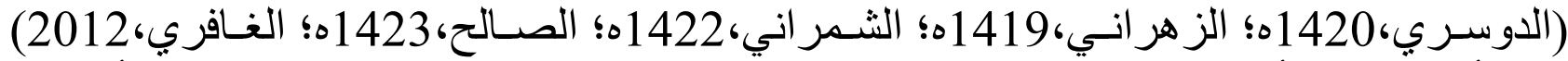

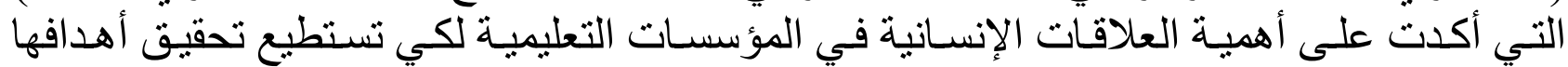

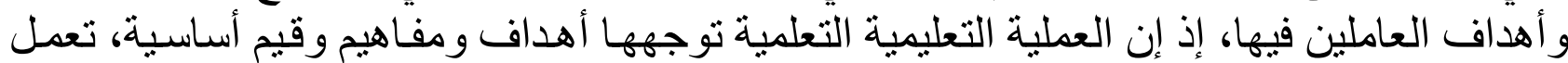
على تكوين شخصية المتعلم الثخصية الإنسانية السوية النية (الأحمري، 2010).

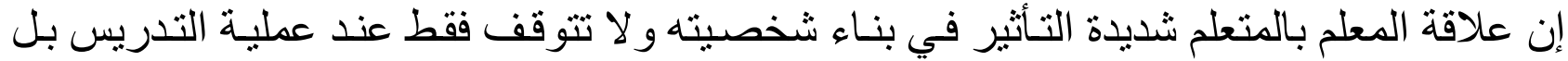

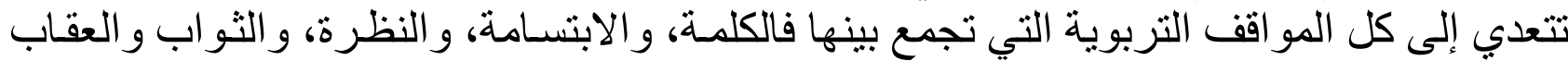

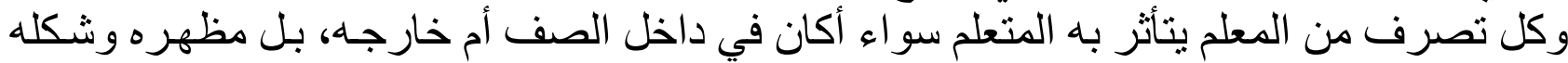

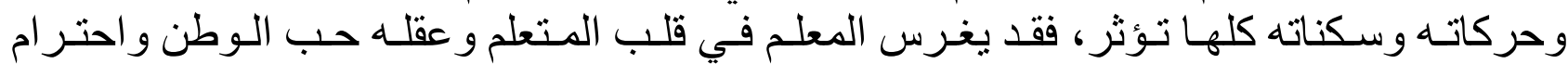

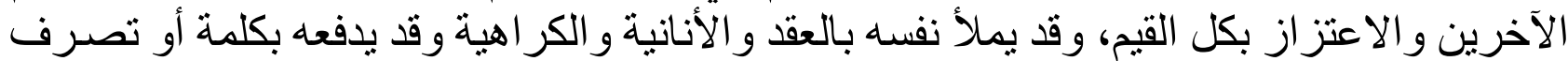

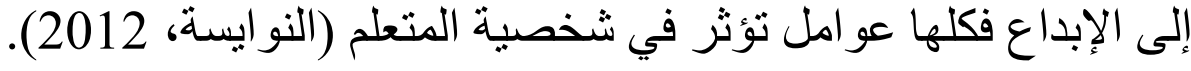

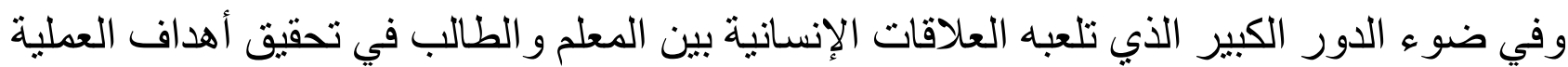

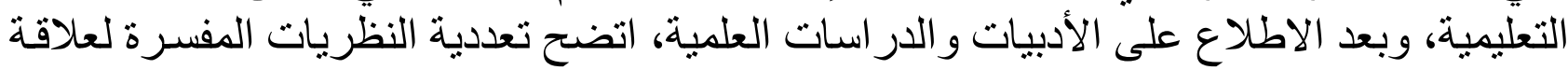




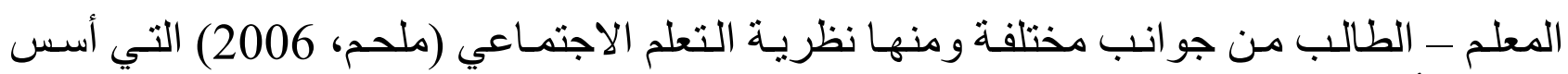

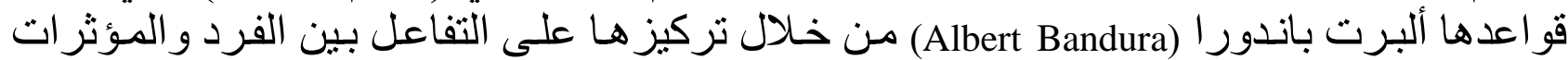

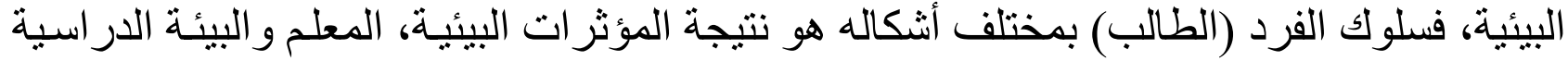

التي يتعرض لها الفرد في ضوء نظامه المعرفي و الفكري، و الثخصي (الزغلول، 2003).

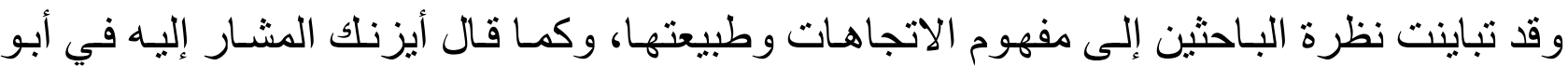

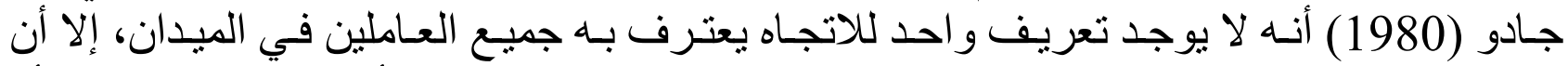

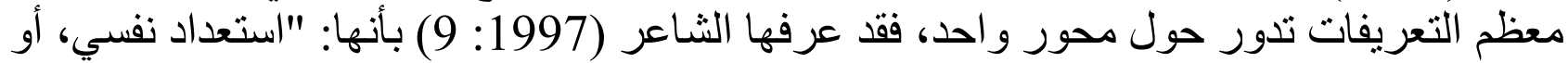

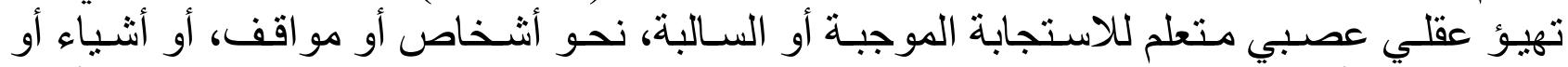

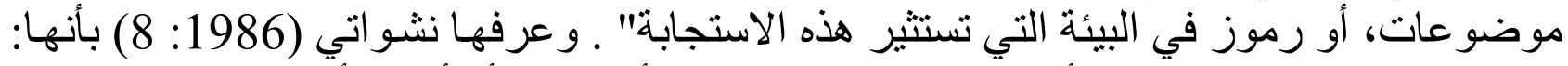

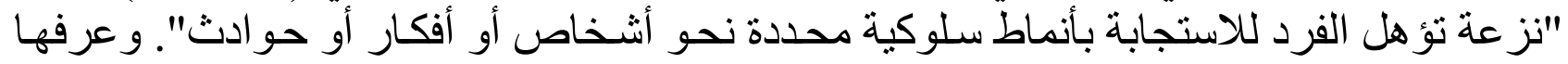

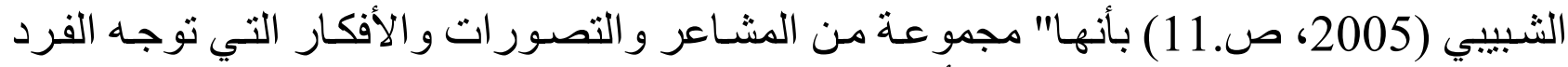

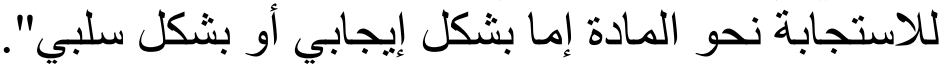

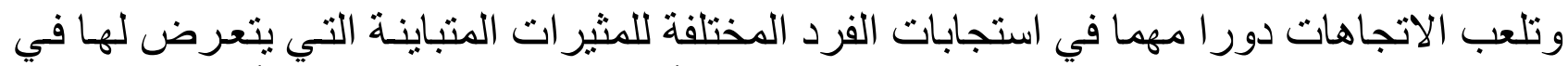

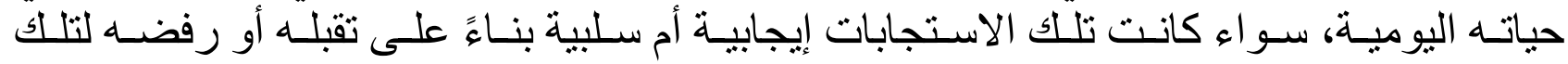

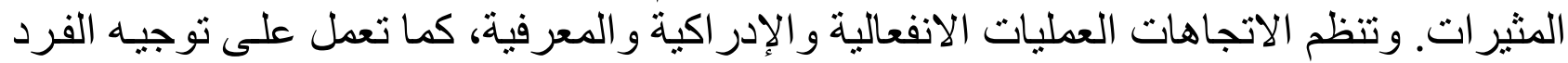

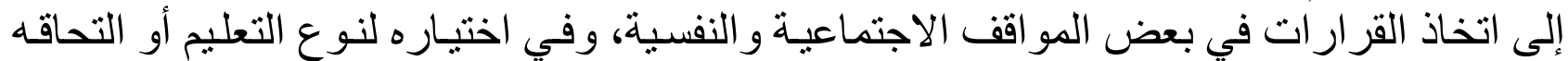

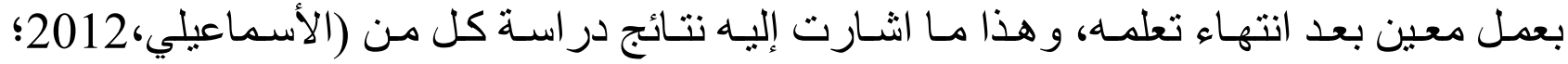

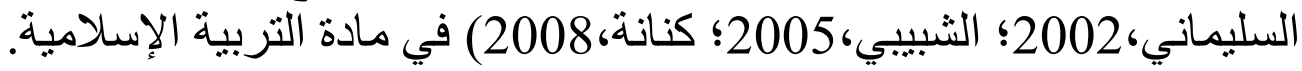

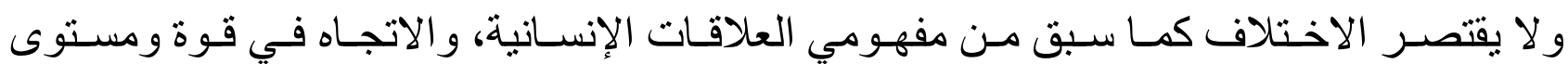

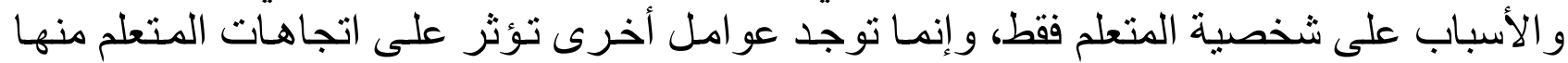

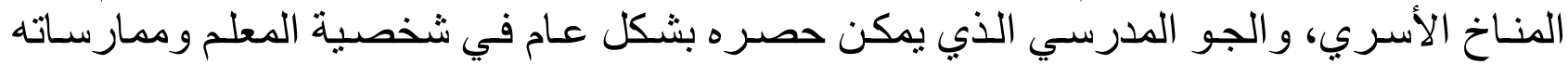

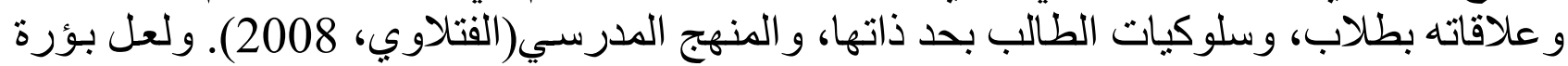

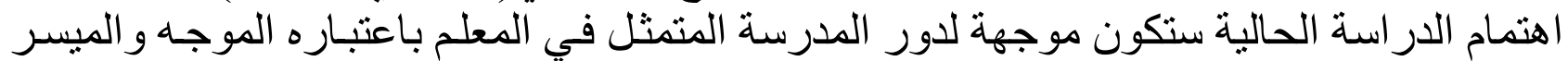
و اليد المباثرة في العملية التعليمية، وباعنباره من أكثر الفئات تأنثير ا في نفية الثية الطالب.

مشكلة الدراسة

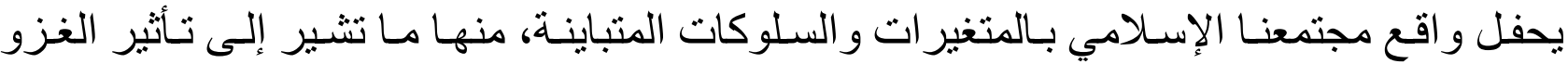

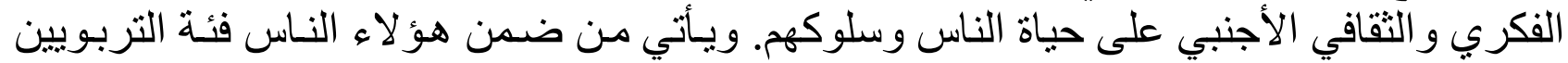

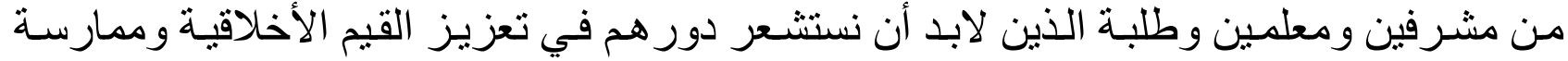

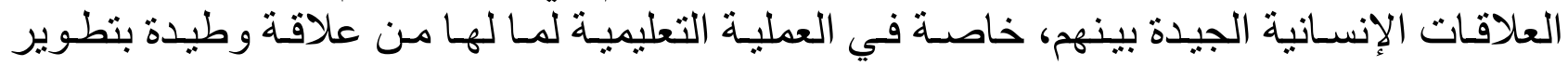

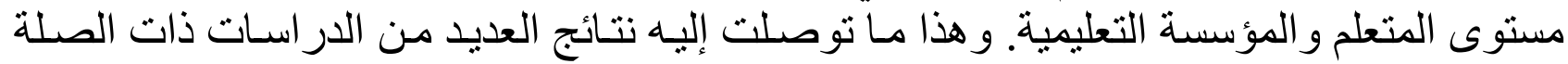

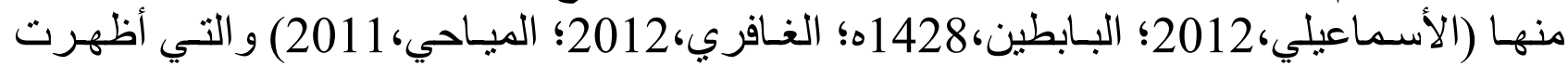
وجود ممارسة للعلاقات الإنسانية في العملية التعليمية واتجاهات إيجابية نحو المادة.

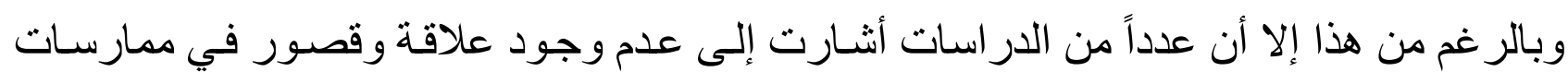

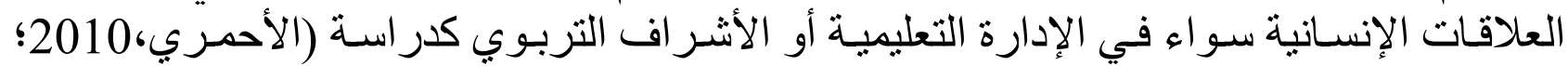

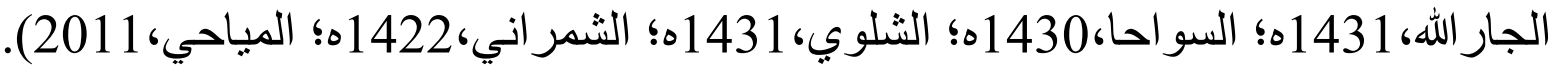




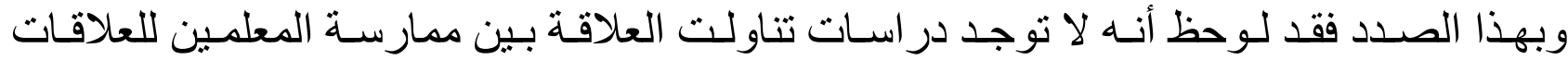
الإنسانية مـع طلبتهم و اتجاهـات طلبتهم نحو المـادة في المر احل التعليميـة، سوى در اسـة البـابطين (1428ه) التي كانت بين ممارسة الأستاذ الجامعي للعلاقفات الإنسـانية وطلبـة كليـة التربيـة، ونظـراً

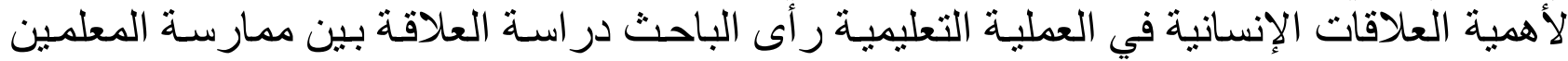

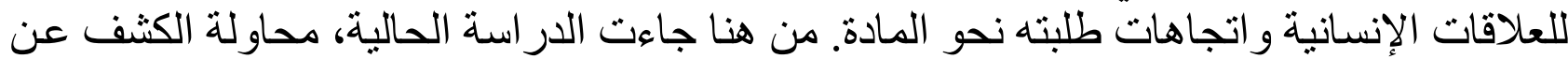

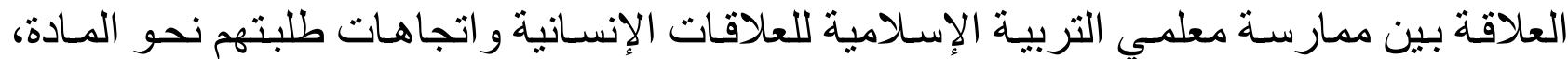
وستركز الدر اسة على بعض المحاور في العلاقات الإنسانية الممارسة من المعلمين ومعرفة مدئ مدى علاقتها باتجاهات طلبتهم نحو المادة.

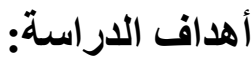

أ. مناقثـة مدى ممارسة معلمي التربية الإسلامية للعلاقات الإنسانية في العملية التعليمية من وجهة نظر طلبتهم. ب. تشخيص اتجاهات طلبة الصف الحادي عشر نحو مادة التربية الإسلامية. الار اسات السابقة دراسة الغافري (2012) هدفت الدر اسة إلى التعرف على مدى ممارسة مشرفي التربيـة الإسـلامية

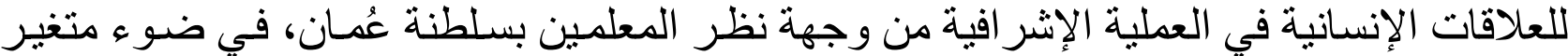

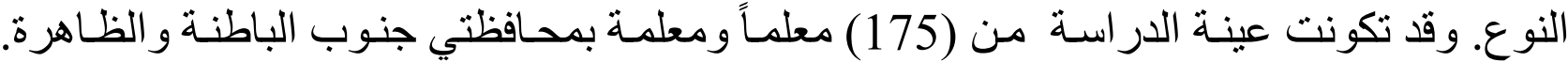

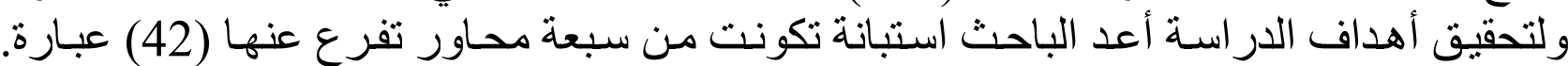

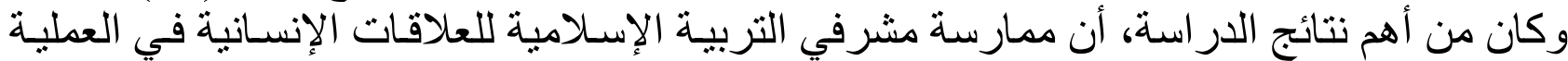

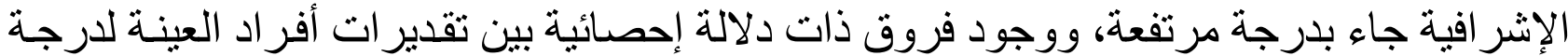

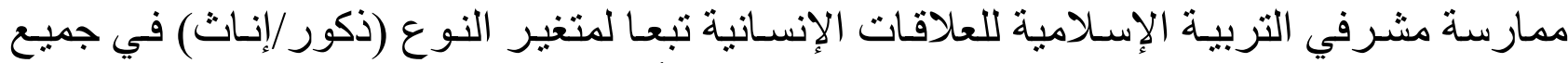

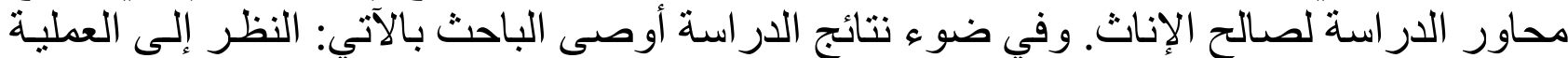
الإشر افية على أنها عملية تربوية تستهدف تطوير أداء المعلمين، لا على أنها عملية تصبد للأخطاء

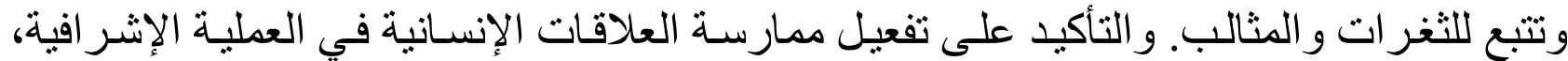
والا هنمام بمحور الثورى لانعراب.

دراسـة الميـاحي (2011) هدفت الدراسـة للتعرف على و اقع مر اعـاة مديري المدارس بسـلطنة

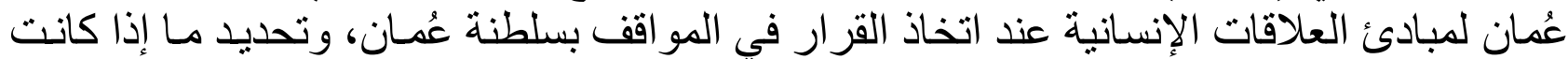

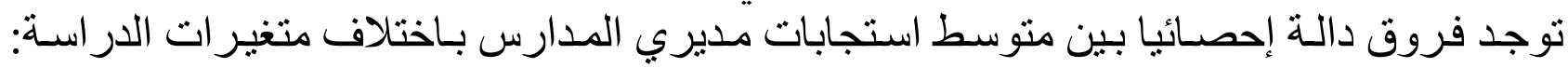

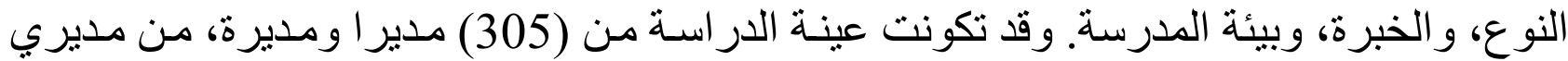

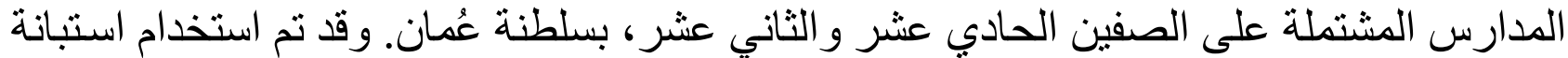

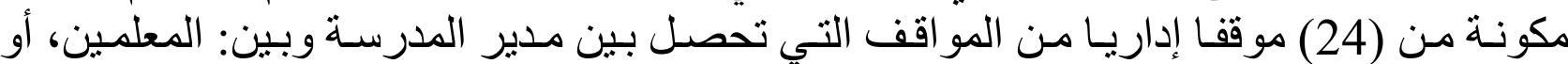

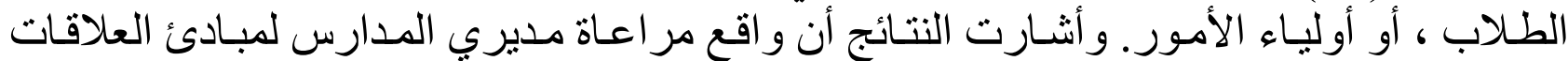

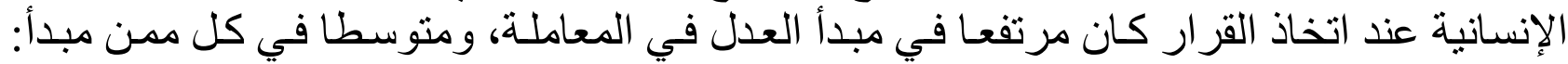

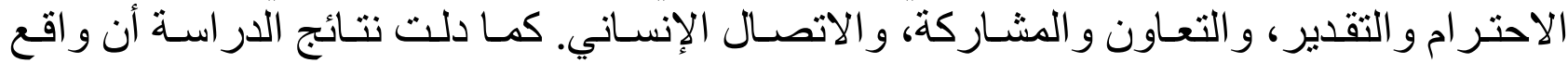

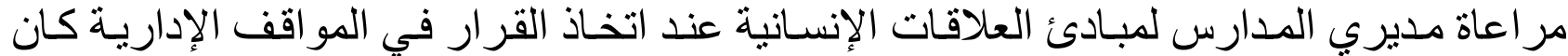

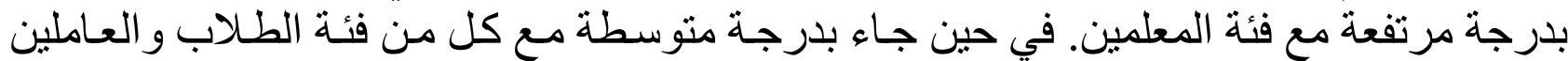

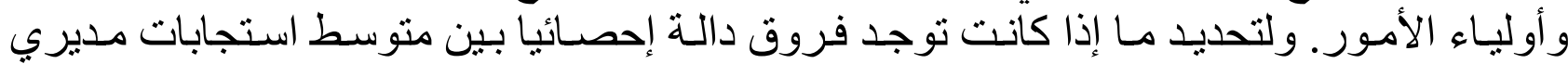




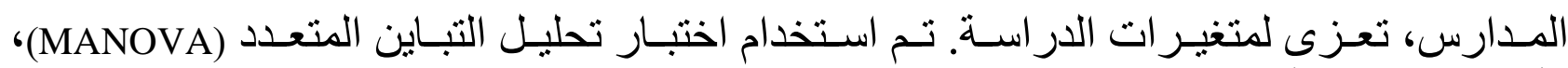

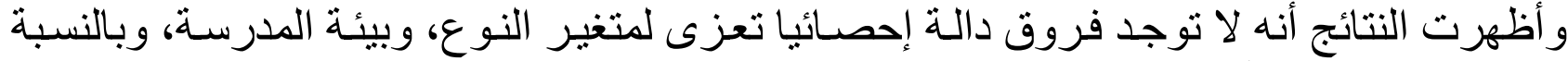

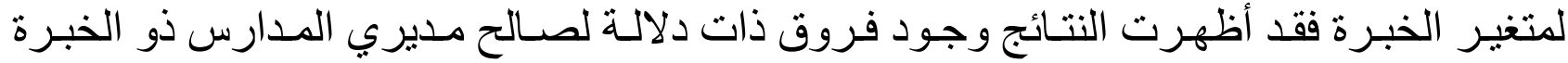
القصيرة. وخلصت الدر اسة إلى عدد من التوصيات، و المقترحات البحثية.

دراسـة الأحمـري (2010/01431)؛ سـعت الدر اسـة إلىى التعـرف على و اقع ممارسـة المشـرفين التربويين ومديري المعاهد العلمية للعلاقات الإنسانية من وجهة نظر المعلمين في المعاهد العلميـة،

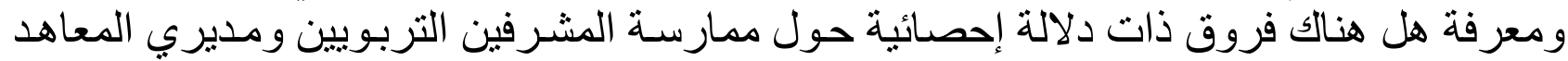

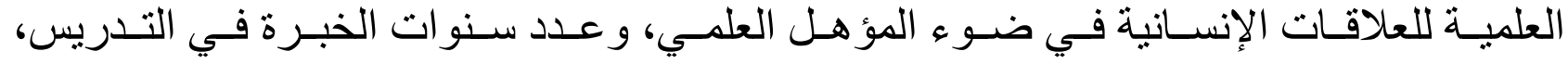
و التخصص، و عدد معلمي المعهد. وتكونت عينة الدر اسة من (701) استبان نشكل (43.9\%) من ون

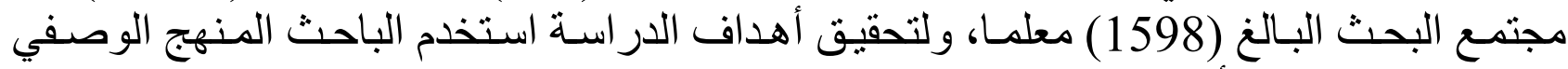

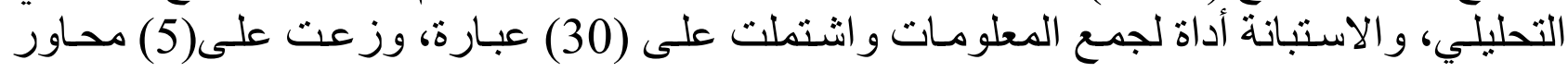

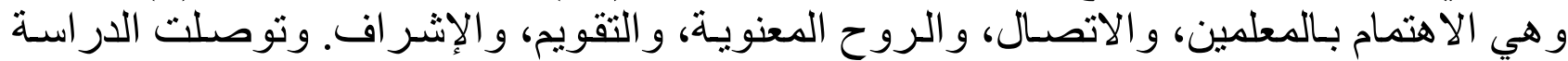

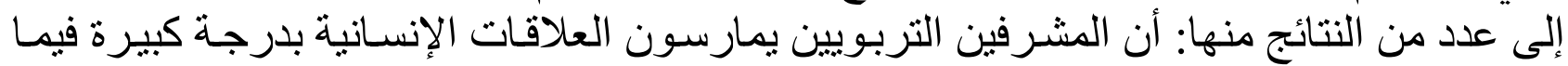

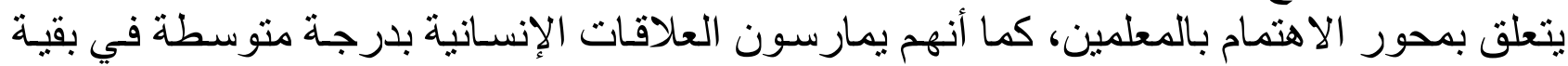

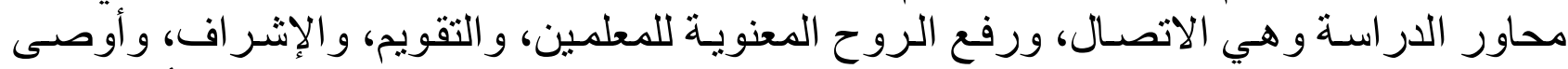

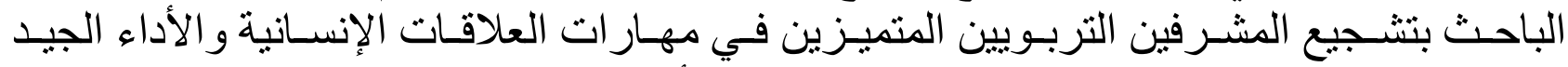

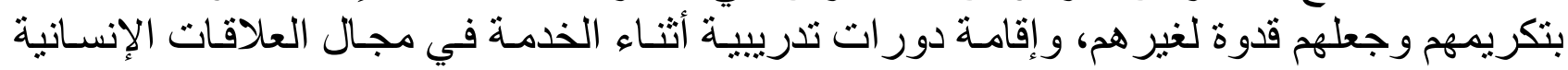
لمديري المعاهد العلمية و المشرفين ومعلمي المعاهد العلمية. دراسة الجار الله (1431هـ/ 2010) هدفت الدر اسـة إلى الكثف عن ون واقع العلاقات الإنسـانية بين

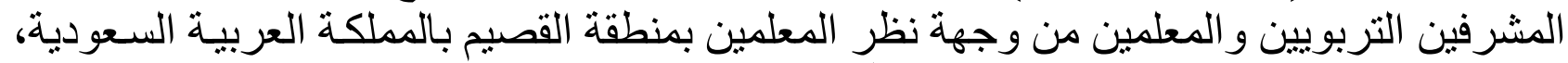

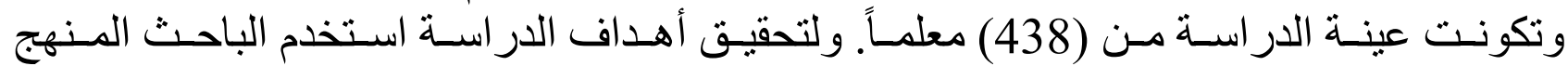

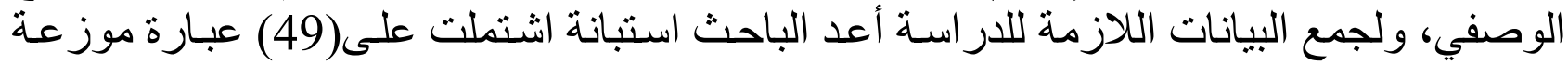

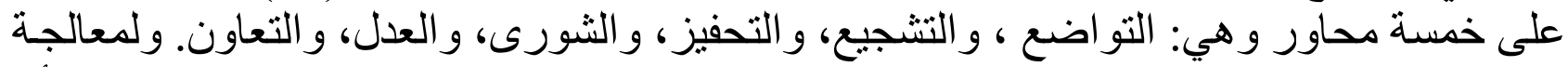

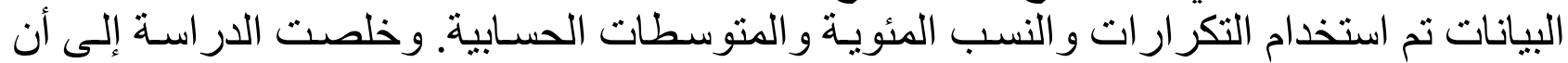
و اقع العلاقات الإنسانية بين المشرفين التربوبين و المعلمين من وجهة نظر المعلمين بمنطقة القصيم

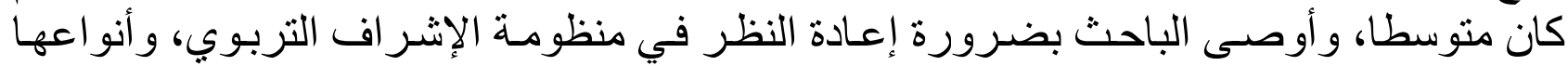

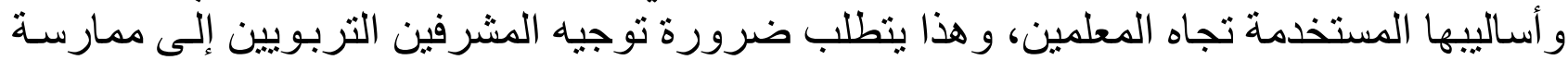

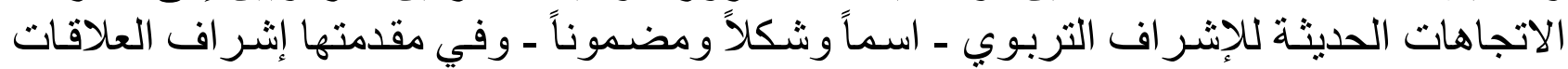
الإنسانية وذللك من خلال دور ات تدريبية وتنشيطية، تهدف إلى تبصير المشـرفين بأهمية استخدام

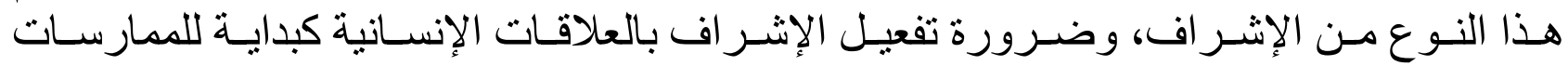
الإشر افية تجاه المعلمين في جميع المجالات (الإدارية ، و التعليمية).

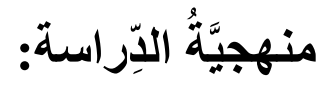

اتبع الباحث المنهج الارتباطي، الذي يعتمد على جمع البيانات من عدد من المتغير ات، وتحديد ما

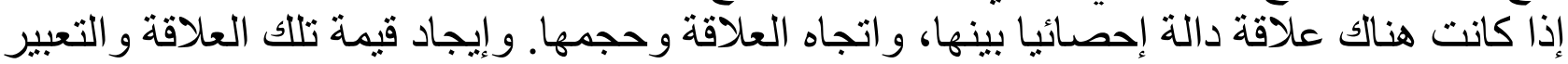

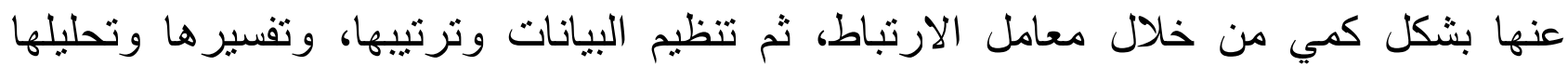
للتوصل إلى استتناجات عامة. عني 


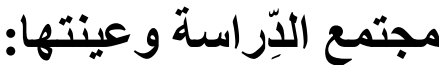

تكون مجتمع الدراسة من طلبة الصف الحادي عشر من التهن التعليم ما بعد الأساسي (11-12)

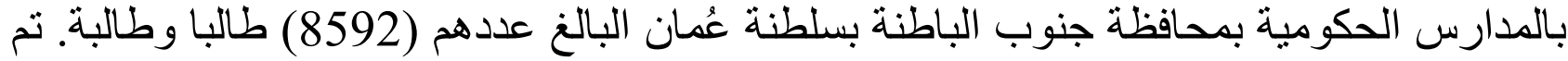
اختيار عينة الدراسة بالطريقة العشوائية وبالتقنية الطبقية وقد تكونت من (19) (383) طالبا وطالبة استنادا لجدول جريسي ومور غان (1970).

أداتا الدِّر اسةة:

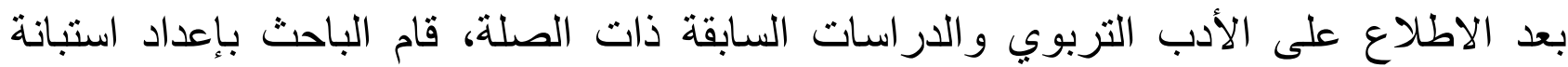

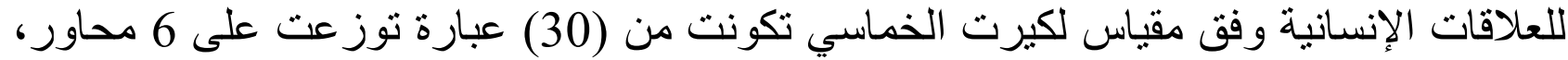

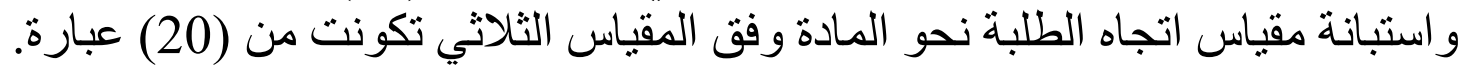

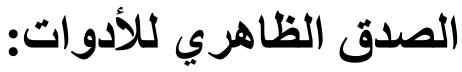

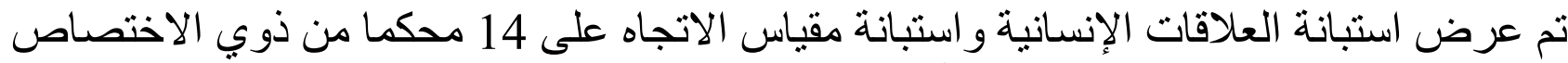

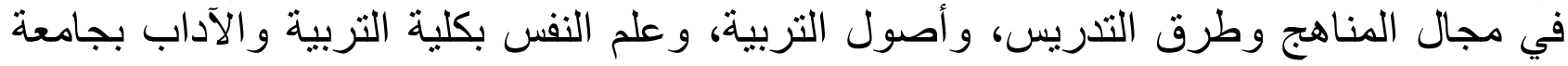

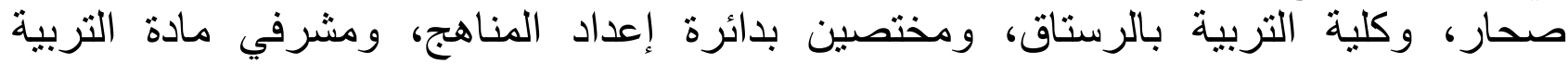

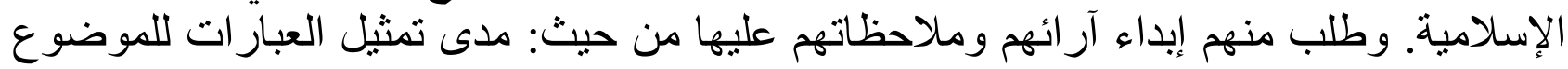
المقاس، وسلامة الصياغة اللغوية. وتقديم الملاحظات و التعديلات للعبار ات بما يرونه مناسبا.

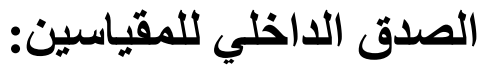

تم استخر اج معاملات ارتباط فقرات الاستبانتين مع الدرجة الكلية بتطبيق المقياسين على عينة

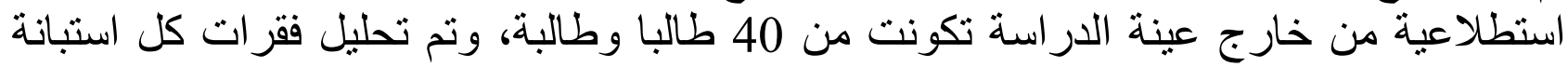

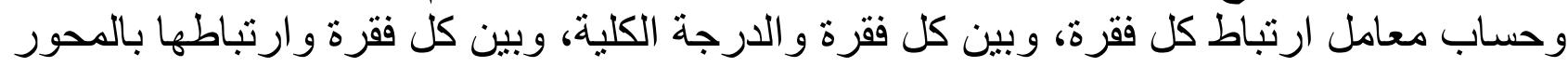

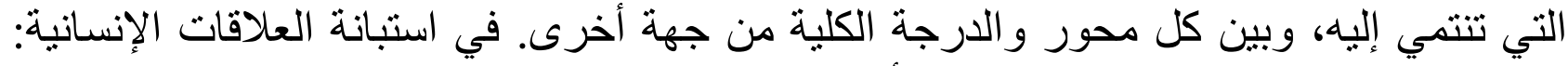

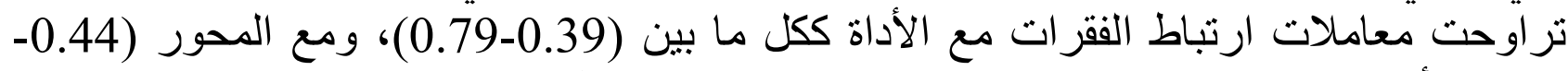

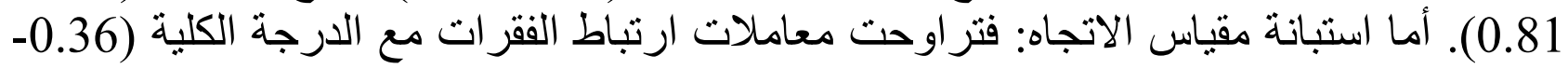

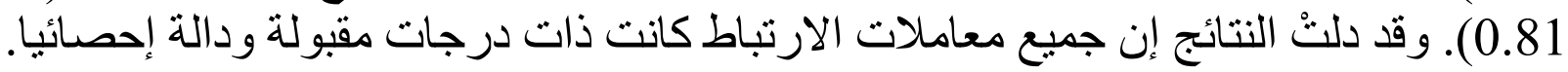

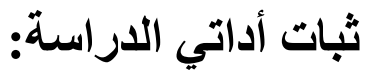

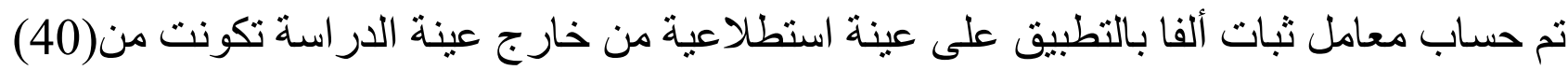

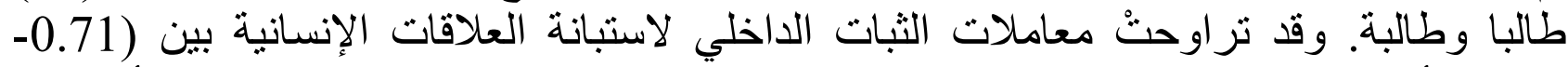

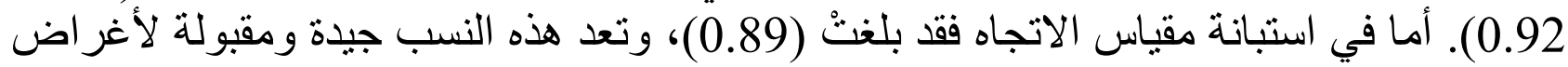
البحث العلمي.

\section{المعالجات الإحصائية}

تم معالجة البيانات إحصائياً باستخدام برنامج الحزم الإحصائية للعلوم الإنسانية والاجتماعية

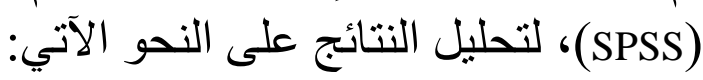
أ. معادلة ألفا كرونباخ (Cronbach's Alpha) لتحديد معامل الثبات. ب. معامل ارتباط بيرسون peresone للتأكد من صدق الاتساق الداخلي بين كل محور و الدرجة 
ت. التحليل الوصفي لحساب التكرارات، والمتوسطات الحسابية، والنسب المئوية، و الانحر افات المعيارية. ث. اختبار "ت" (T-test) لحساب الفروق لمتغير ثنائي. نتائج الدراسة: الإجابة عن أسئلة الدر اسة:

السؤال الأول: ما مدى ممارسة معلمي التربية الإسلامية للعلاقات الإنسانية مع طلبة الصف الصف

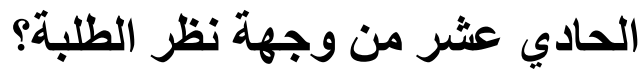

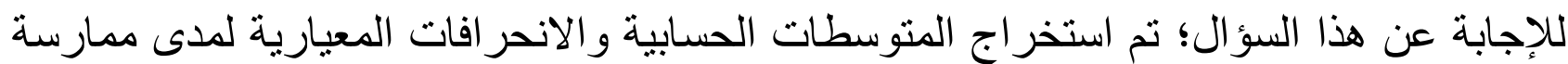

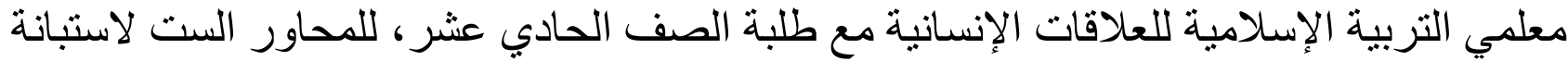

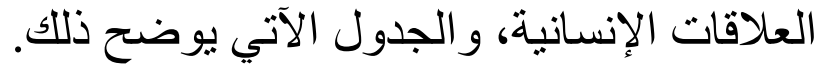

جدول (1) المتوسطات الحسابية والانحر افات المعيارية للمحاور الست لاستبانة العلاقات الإنسانية مرتبة تناز لياً

\begin{tabular}{|c|c|c|c|c|c|}
\hline التقدير & الانحر اف المعياري & المتوسط الحسابي & المحور & الرقم & الرتبة \\
\hline مر تفع جدا & .745 & 4.20 & التو اضع & 2 & 1 \\
\hline 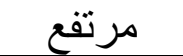 & .639 & 4.18 & الاحترام & 1 & 2 \\
\hline 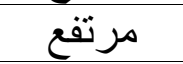 & .757 & 4.15 & الثقة بالنفس & 6 & 3 \\
\hline مرتفع & .695 & 4.12 & العدل و المساو اة & 3 & 4 \\
\hline مرتفع & .580 & 4.08 & الوضوح & 4 & 5 \\
\hline مرتفع & .773 & 3.83 & التعاون & 5 & 6 \\
\hline مرتفع & .577 & 4.09 & كعل معل المحاور & & \\
\hline
\end{tabular}

يبين الجدول (1) أن المتوسطات الحسابية قد تر اوحت ما بين (3.83) - (4.20)، حيث جاء محور

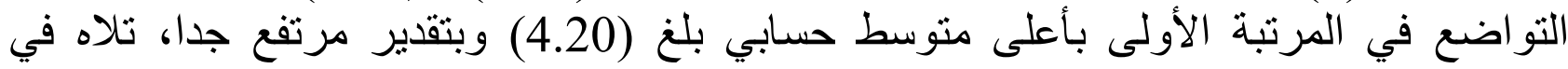

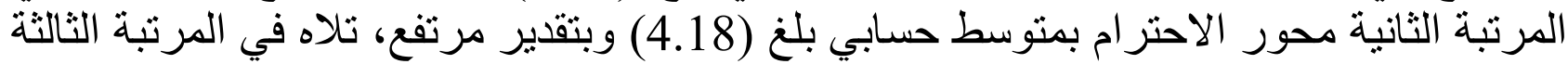

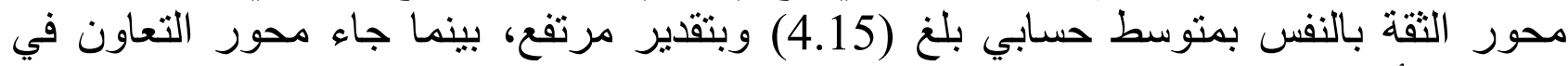

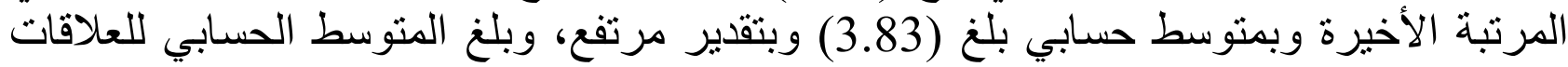
الانسانية ككل (4.09) وبتقدير مرتفع.

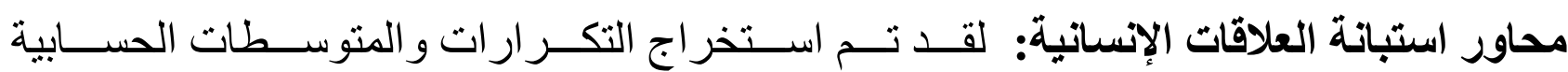

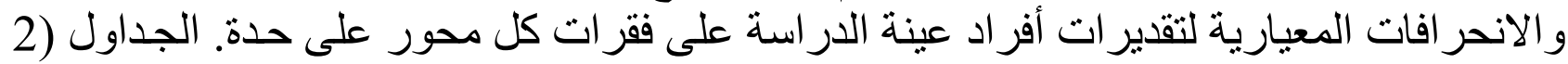

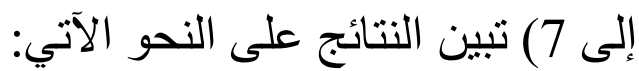
المحور الأول: الاحترام 
جدول (2) المتوسطات الحسابية و الانحر افات المعيارية و التكر ار ات لفقر ات محور الاحتر ام مرنبة تناز لياً

\begin{tabular}{|c|c|c|c|c|c|}
\hline التقديز & الانتحراف & المتوسط المسبي & عبارات المحور الأول & الرقم & 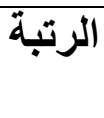 \\
\hline مرتفع & .792 & 4.43 & يتعامل باحتر ام مع الطلاب. & 6 & 1 \\
\hline مرتفع & .928 & 4.27 & ويحافظ عليها. على العلاقات الطيبة مع جميع الطلاب & 4 & 2 \\
\hline مرتفع & .926 & 4.16 & يحترم المعلم مشاعر الطلاب. & 1 & 3 \\
\hline مرتفع & .874 & 4.14 & المدبل المعلم اقتر احات الطلاب وفق النظام & 2 & 4 \\
\hline 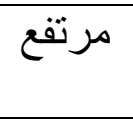 & 1.043 & 4.07 & 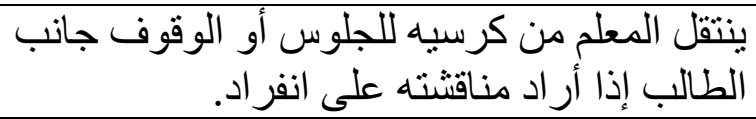 & 5 & 5 \\
\hline مرتفع & 1.031 & 4.04 & السخدم المعلم نقده لطلبته بصورة لطيفة خالية من & 3 & 6 \\
\hline مرتفع & .639 & 4.18 & معدل عبارات المحور الأول & & \\
\hline
\end{tabular}

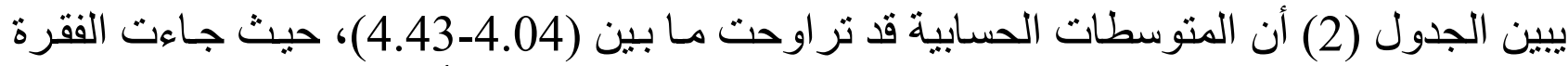

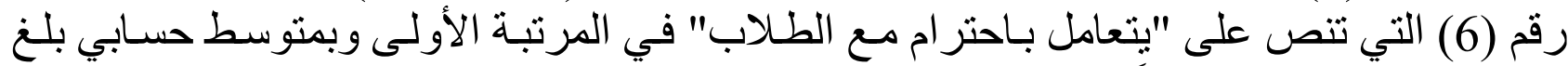

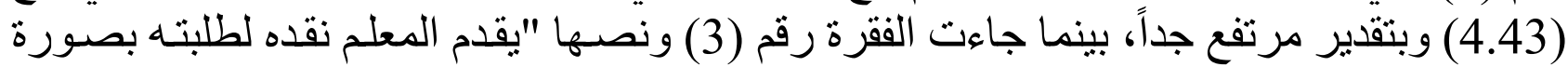

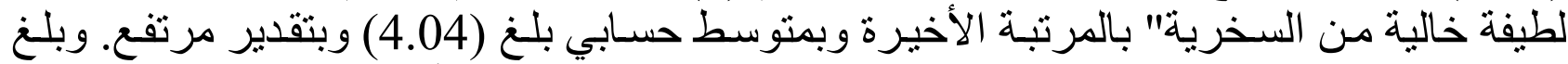

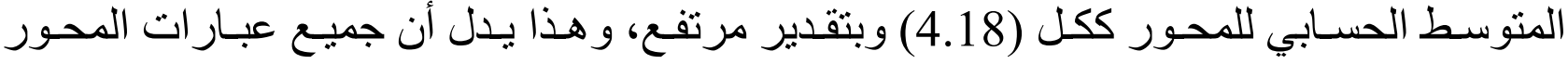
تمارس بشكل مرتقع. المحور الثاني: التواضع

جدول (3) المنوسطات الحسابية والانحر افات المعيارية والتكرار ات لفقرات محور التو اضع مرتبة تنتاز لياً

\begin{tabular}{|c|c|c|c|c|c|}
\hline التقدير & الانحرياري & المثتوسط الحسبي & عبارات المحور الثاني & الرقم & 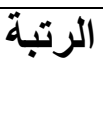 \\
\hline مرتفع جدا & .957 & 4.27 & يبادر بإلقاء التحية في أي مكان. & 8 & 1 \\
\hline مرتفع جدا & .931 & 4.23 & يمتاز بالبشاشة وطلاقة الوجه ولين الجانب. & 7 & 2 \\
\hline مرتفع جدا & .931 & 4.21 & يتمتع بأسلوب مرح مع الاحتفاظ بقوة & 9 & 3 \\
\hline مرتفع & 1.083 & 4.09 & يعتذر إذا بدر منه ما يدعو للاعتذار. & 10 & 4 \\
\hline مرتفع جدا & .745 & 4.20 & معدل عبارات المحور الثاني & & \\
\hline
\end{tabular}

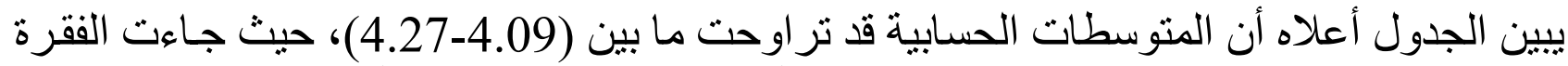

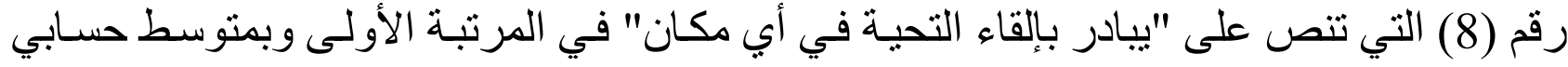

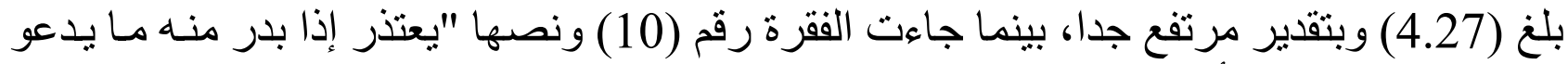

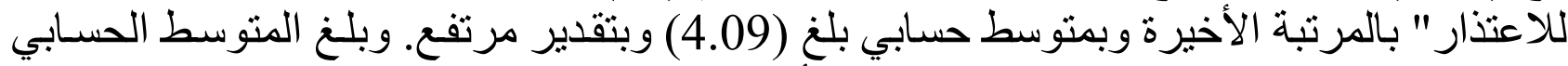
للمحور ككل (4.20) وبتقدير مرتفع، وهذا يدل أن ممارسة المعلمين لهذه البنود ممارسة مرتفعة. 
المحور الثالث: العدل والمساواة

جدول (4) المتوسطات الحسابية والانحر افات المعيارية والتكر ار ات لفقرات محور العدل و المساو اة مرنبة تنازئ لانياً

\begin{tabular}{|c|c|c|c|c|c|}
\hline التقدير & الالنحراف & المتوسط الحسبي & عبارات المحور الثالث & الرقم & 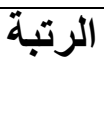 \\
\hline مرتفع & .962 & 4.39 & تصترف بالخطأ العلمي إذا وقع منه ويعمل على & 15 & 1 \\
\hline مرتفع & 1.182 & 4.09 & يساوي بين الطلاب في المعاملة و الحقوق و الو اجبات. & 11 & 2 \\
\hline مرتفع & .943 & 4.07 & بر اعي قدر ات الطلبة و إمكانياتهم عندما يطلب القيام & 12 & 3 \\
\hline مرتفع & .884 & 4.07 & يتسم تقويمه لأداء الطلاب بالموضو عية. & 14 & 4 \\
\hline مرتفع & .983 & 3.99 & يتجنب المجاملة السلبية في تعامله مع الطلاب. & 13 & 5 \\
\hline مرتفع & .695 & 4.12 & معدل عبارات المحور الثالث & & \\
\hline
\end{tabular}

يبين الجدول (4) أن المتوسطات الحسابية قد تراوحت مـا بين (3.99-4.39)، حيث جاءت الفقرة رقم (15) و التي تتص على "بعترف بالخطأ العلمي إذا وقع منه ويعمل على تصحيحه" في المرتبـة

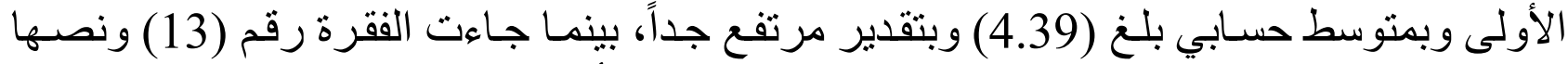
"يتجنب المجاملة السلبية في تعامله مـع الطلاب" بالمرتبـة الأخبرة وبمتوسط حسـابي بلـغ (3.99) وبتقدير مرتفع. وبلغ المتوسط الحسابي للمحور ككل (4.12) وبتقدير مرتفع، و هذا بدلٍ أن ممارسـة فئة

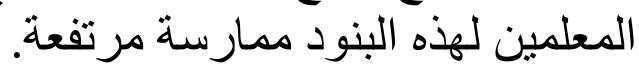
المحور الرابع: الوضوح جدول (5) المتوسطات الحسابية و الانحر افات المعيارية و التكرار ات لفقر ات محور الوضوح مرتبة تناز لياً

\begin{tabular}{|c|c|c|c|c|c|}
\hline التقدير & الانتحراف & المتوسط الحسبي & عبارات المحور الرابع & 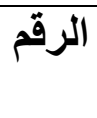 & 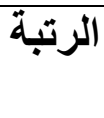 \\
\hline مرتفع & .711 & 4.24 & يحدد الأهداف التعليمية التي يسعى لتحقيقها. & 16 & 1 \\
\hline مرتفع & .793 & 4.24 & المادة. أساليب المتابعة و التقويم لأداء الطلاب في & 17 & 2 \\
\hline مرتفع & .780 & 4.10 & العام. الإجر اءات التنفيذية للعمل مع الطلاب خلال & 18 & 3 \\
\hline 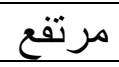 & .864 & 4.01 & تتسم توجيهاته بعدم التناقض في المو اقف المنتـابهة. & 19 & 4 \\
\hline مرتفع & 1.314 & 3.83 & كالحرضوب) التربوبة استخدام التقنياتة الحديثة في المادة الدر اسيةل. & 20 & 5 \\
\hline مرتفع & .580 & 4.08 & معدل عبارات المحور الرابع & & \\
\hline
\end{tabular}

يبين الجدول (5) أن المتوسطات الحسابية قد تراوحت ما بين (3.83-4.24)، حيث جاءت الفقرتان رقم (16 و 18) وتتصان على "يحدد الأهداف التعليمية التي يسعى لتحقيقها" و "يحدد أساليب المتابعة و التقويم لأداء الطلاب في المادة" في المرتبة الأولى وبمتوسط حسابي بلغ (4.24) وبتقدير مرتفع جداً، بينما جاءت الفقرة رقم (20) ونصها "يعرض طريقة استخدام التقنيات 
(الوسائل كالحاسوب) التربوية الحديثة في المادة الدر اسية" بالمرتبة الأخيرة وبمتوسط حسابي بلغ

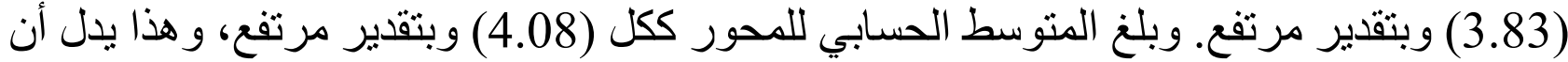

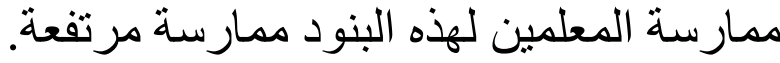
المحور الخامس: التعاون جدول (6) المتوسطات الحسابية والانحر افات المعيارية والتكر ارات لفقر ات محور التعاون مرنبة تنازلياً

\begin{tabular}{|c|c|c|c|c|c|}
\hline التقدير & الانحراف المعياري & المتوسط الحسبي & عبارات المحور الخامس & الرقم & 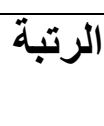 \\
\hline مرتفع & .994 & 4.17 & يوفر مناخا جيدا لإنجاح الحصة الدر اسية. & 21 & 1 \\
\hline مرتفع & 1.023 & 4.15 & يقدر بعض الظروف الخاصة بالطلاب. & 23 & 2 \\
\hline مرتفع & .944 & 4.06 & يعلى على توثيق العلاقات الطيبة بين الطلاب ويعل بينهم. & 24 & 3 \\
\hline مرتفع & 1.046 & 3.83 & الطساب. في حل المشكلات المدرسية التي تو اجه & 22 & 4 \\
\hline وسط & 1.340 & 2.92 & يمكن الاتصال به عبر قنو ات التو اصل الاجتماعي & 25 & 5 \\
\hline مرتفع & .773 & 3.83 & معدل عبارات المحور الخامس & & \\
\hline
\end{tabular}

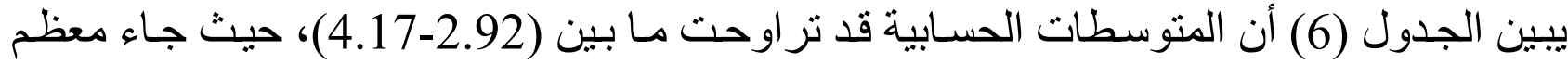

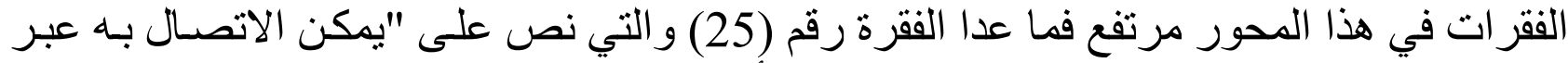

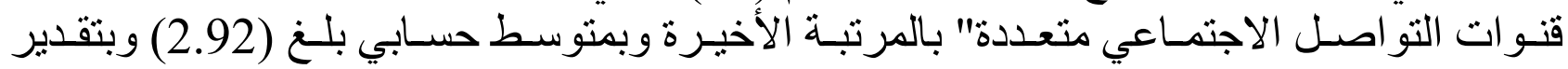

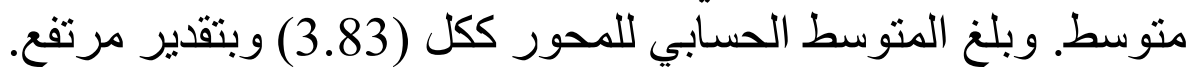
المحور السادس: الثقة بالنفس جدول (7) المتوسطات الحسابية والانحر افات المعيارية والتكر ار ات لفقر ات محور الثقة بالنفس بلفس مرتبة تنتازلياً

\begin{tabular}{|c|c|c|c|c|c|}
\hline التقدير & الالمعراف & المستوسط المبي & عبارات المحور السادس & الرقم & 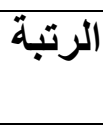 \\
\hline مرتفع & .891 & 4.33 & متمكن في المادة العلمية و أساليبها في مجال تخصصها. & 28 & 1 \\
\hline مرتفع & .966 & 4.22 & تهيئة جو الاطمئنان بين الطلاب في المادة الدر اسية. & 27 & 2 \\
\hline مرتفع & .974 & 4.22 & واؤثر تأثير إيجابيا في تحسين مستوى الطلاب السلوكي & 30 & 3 \\
\hline مرتفع & .980 & 4.17 & يشعهر الطلاب بالثقة في الحصة الدر اسية وأثناء التعامل & 26 & 4 \\
\hline مرتفع & 1.192 & 3.81 & بتحكم في انفعالاته وقت الغضب. & 29 & 5 \\
\hline مرتفع & .757 & 4.15 & معدل عبارات المحور السادس & & \\
\hline
\end{tabular}




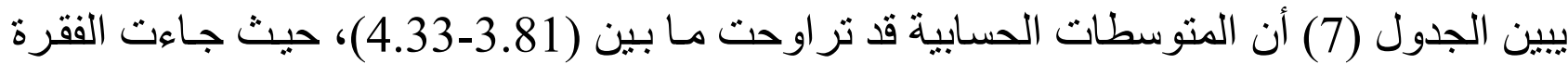

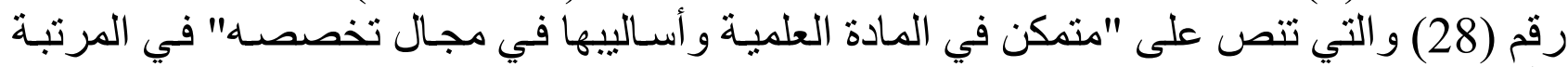

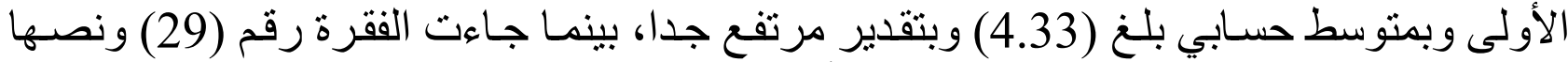

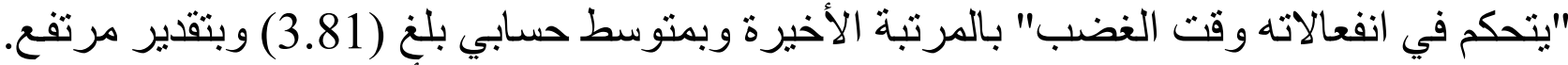

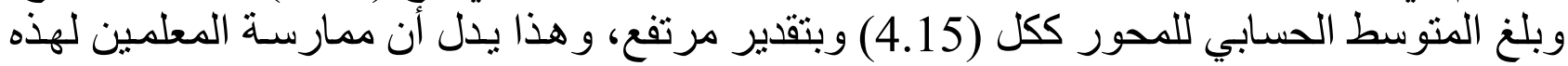
البنود ممارسة مرتفعة.

السؤال الثاني: ما مستوى اتجاهات طلبة الصف الحادي عشر نحو مادة التربية الإسلامية؟

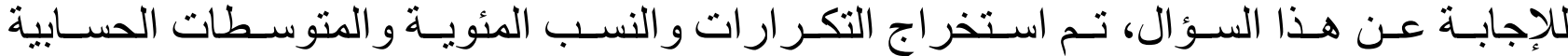

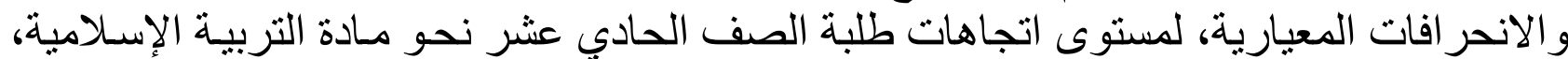
و الجدول (8) يوضح ذللك.

الجدول (8) استجابات عينة الدر اسة حول اتجاهات الطلبة نحو مادة التربية الإسلامية

\begin{tabular}{|c|c|c|c|c|c|}
\hline التقدير & الانحر افعياري & المتوسط الحسبي & عبارات محور اتجاهات الطلبة نحو المادة & الرقم & 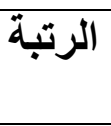 \\
\hline 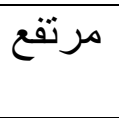 & 0.736 & 2.98 & أرى معظى الحفظ. موضو عات مادة التربية الإسلامية تعتمد & 16 & 1 \\
\hline 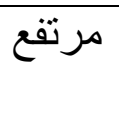 & 0.751 & 2.88 & أرىى مادة التربية الإسلامية تعتمد فقط على الدروس & 15 & 2 \\
\hline 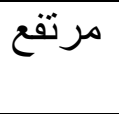 & 0.428 & 2.81 & و تغرس مادة التربية الإسلامية في نفسي المبادئ و القيم & 8 & 3 \\
\hline 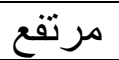 & 0.425 & 2.78 & أحب در اسة التربية الإسلامية لأهميتها في و اقع الحياة. & 5 & 4 \\
\hline 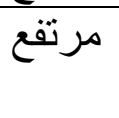 & 0.509 & 2.73 & و النطق التربية الإسلادية تساعدني في اداء العبادات & 7 & 5 \\
\hline 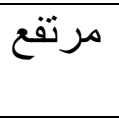 & 0.577 & 2.58 & تحثني مادة التربية الإسلامية على بناء علاقات جيدة & 12 & 6 \\
\hline 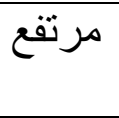 & 0.585 & 2.55 & ومدبعة التربية الإسلامية لأنها تتضمن موضو عات شائقة & 16 & 7 \\
\hline 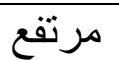 & 0.563 & 2.54 & تنمي لديَ مادة التربية الإسلامية الجانب الروحي و الصبر و التحمل. & 3 & 8 \\
\hline مرتفع & 0.715 & 2.53 & أفرح عندما يغيب معلم التربية الإسلامية عن الحصة. & 8 & 9 \\
\hline مرتفع & 0.613 & 2.51 & أتفاعل كثير امع المعلم في حصة التربية الإسلامية. & 17 & 10 \\
\hline مرتفع & 0.630 & 2.49 & يعجبني التطبيق العملي و المشاركة مع زملائي في حصة التربية الإسلامية. & 14 & 11 \\
\hline مرتفع & 0.593 & 2.40 & أشعر بالسعادة عندما يدخل معلم التزبية الإسلامية إلى الصف. & 6 & 12 \\
\hline مرتفع & 0.603 & 2.35 & أشعر بالملل في حصة التربية الإسلامية. & 5 & 13 \\
\hline مرتفع & 0.701 & 2.34 & أحس بالارتياح للوسائل التعليمية في تدريس مادة التربية الإسلامية. & 18 & 14 \\
\hline وسط & 0.613 & 2.31 & أُشعر بالضيق لأسلوب المعلم في تدريس التربية & 7 & 15 \\
\hline وسط & 0.565 & 2.3 & أتمنى أن تنتهي حصة التربية الإسلامية بسر عة. & 12 & 16 \\
\hline وسط & 0.632 & 2.29 & أرىى إن در اسة التربية الإسلامية لا تقدم لي شيئا في & 16 & 17 \\
\hline
\end{tabular}


IJASOS- International E-Journal of Advances in Social Sciences, Vol. VI, Issue 18, December 2020

\begin{tabular}{|c|c|c|c|c|c|}
\hline وسط & 0.551 & 2.23 & الإشعامية. أشيق و الضجر عند قدوم حصة التربية & 15 & 18 \\
\hline وسط & 0.752 & 1.98 & أرى من الضروري زيادة حصص مادة التربية الإسلامية. & 13 & 19 \\
\hline منخفض & 0.767 & 1.64 & أتمنى أن أصبح معلما لمادة التربية الإسلامية. & 19 & 20 \\
\hline مرتفع & .217 & 2.46 & معدل عبارات محور اتجاهات الطلبة نحو المادة & & \\
\hline
\end{tabular}

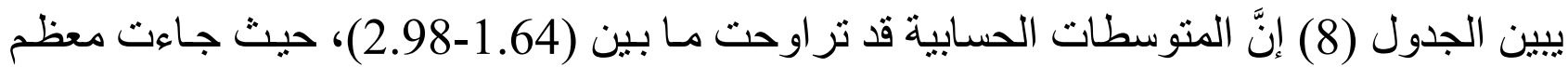

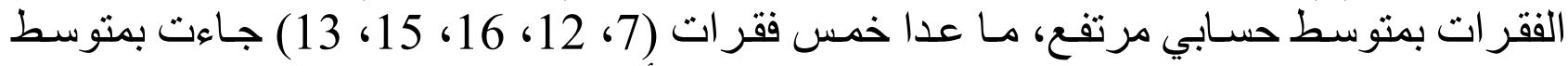

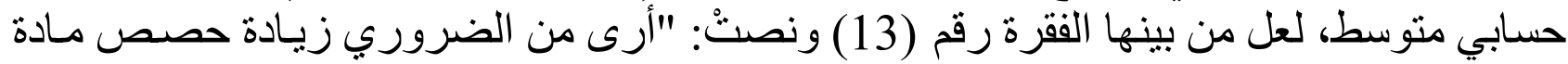

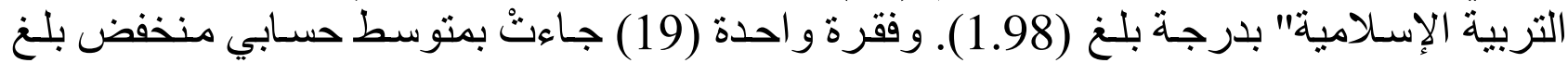

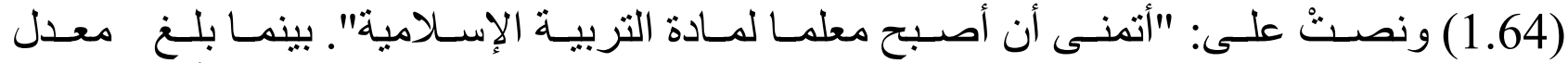

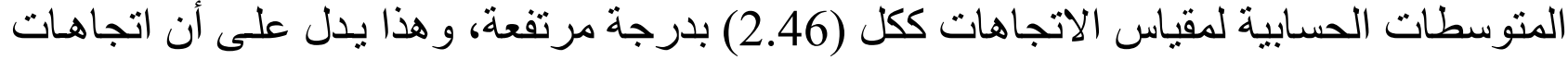
الطلبة نحو مادة التربية الإسلامية مرتفع و إيجابي.

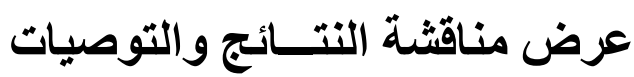

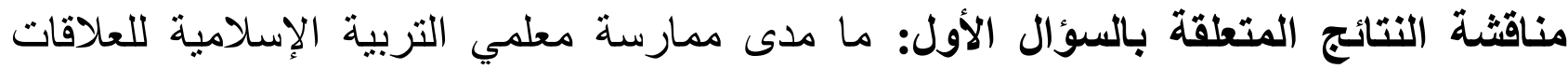

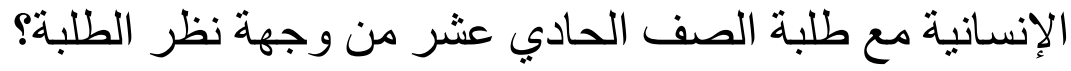

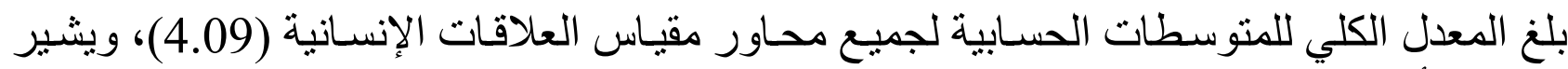

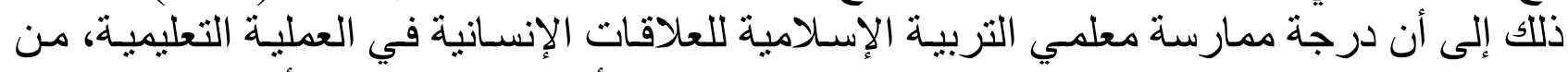

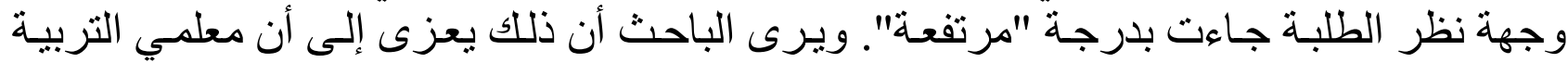

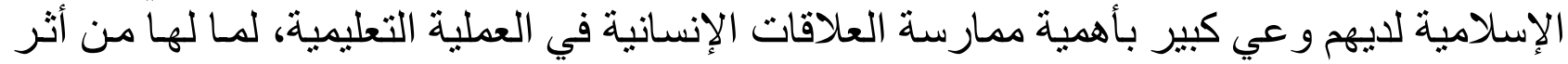

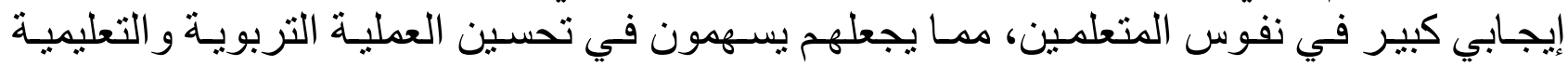
وتطوير ها.

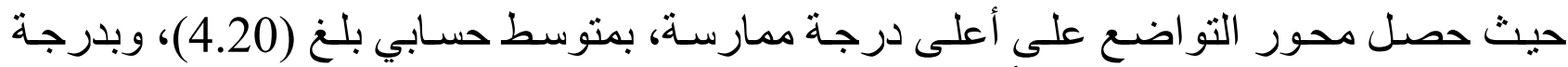
ممارسة "مرتفعة". ويرى الباحث أن ذلك يعزى إلى الاهتمام الذي يوليهـ معلمو التربيـة الإسـلامية

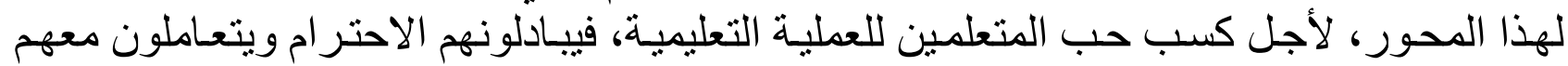

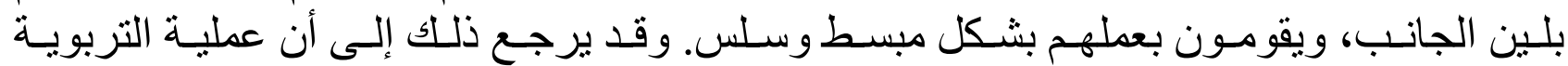

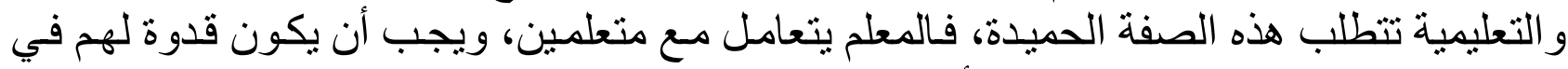

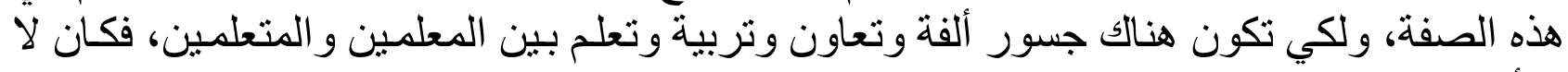
بد أن يتصف بصفة التو اضع.

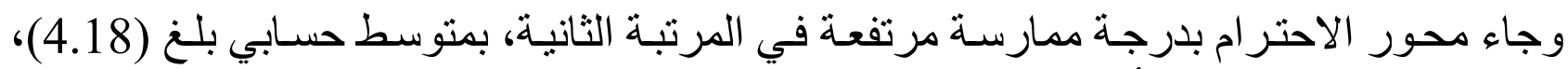

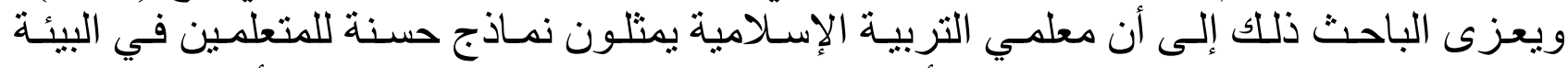

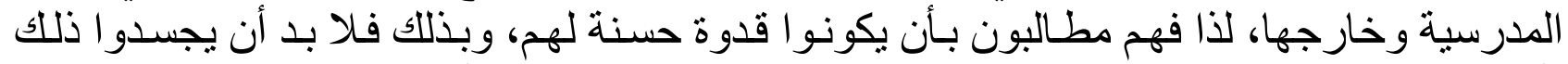

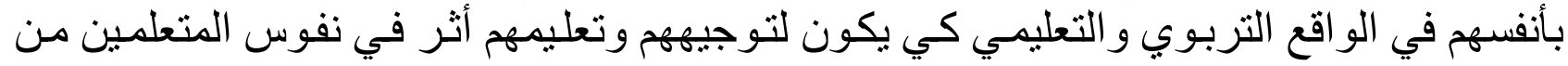
احتر ام وتقدير.

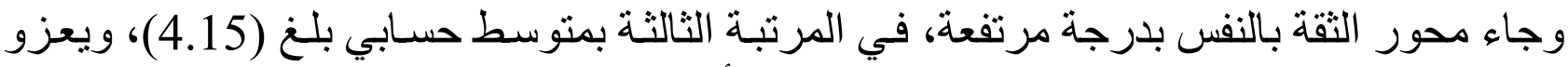

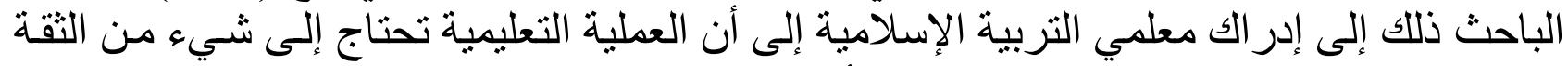

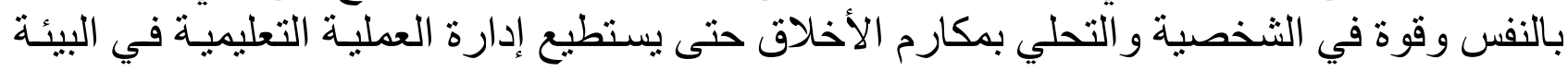




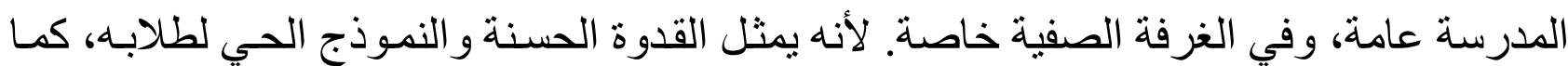

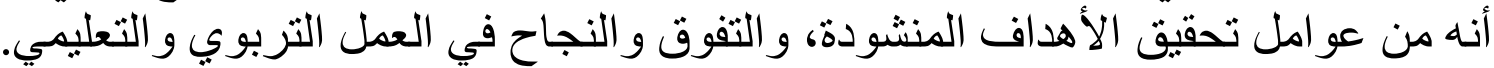

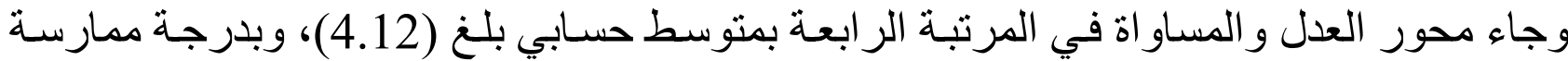

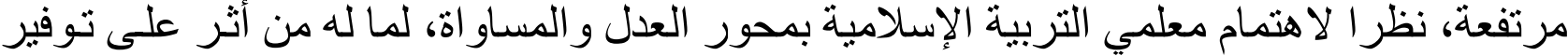

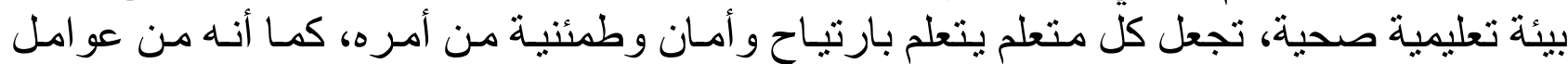
التفوق و النجاح في العمل التربوي.

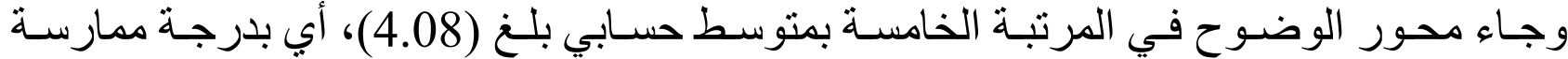

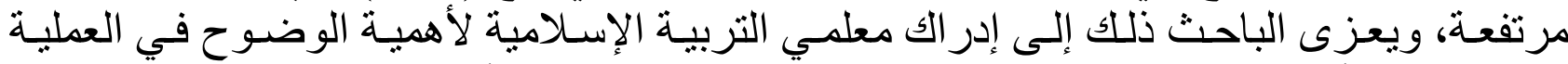

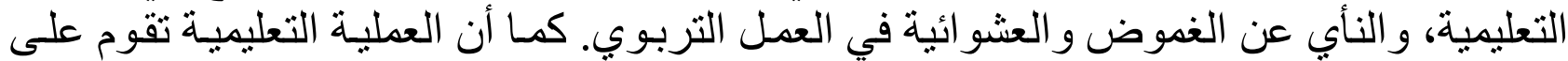

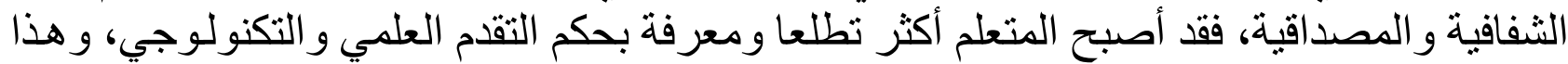
يعطي مساحة للحو ار و النقاش بين المعلمين و المتعلمين.

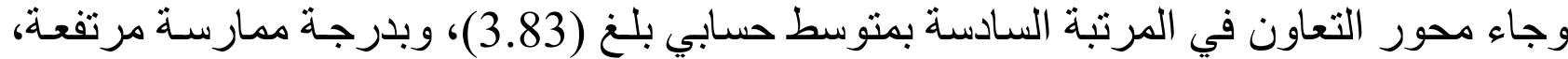

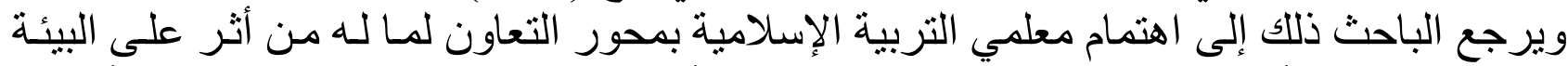

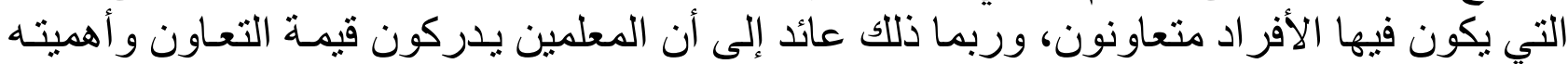

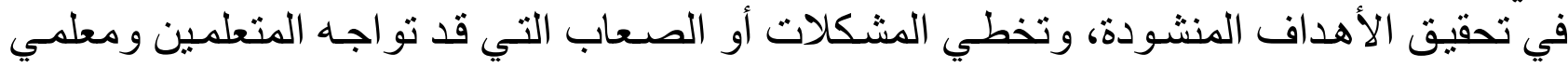

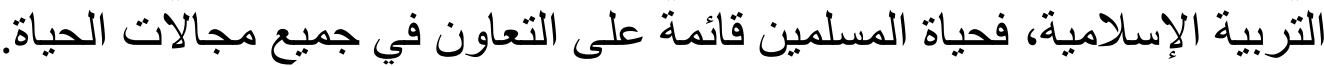

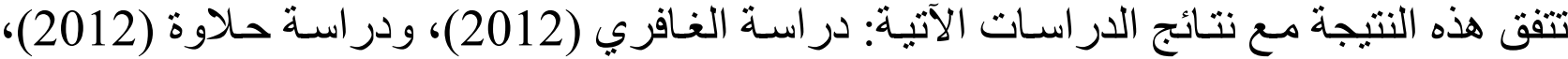
ودر اسة السو احا (2009)، ودر اسة الثنلوي (2007)، التي أَثَارت إلى أن العلاقات الإنسـانية بين

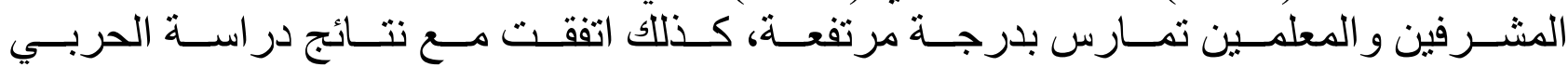

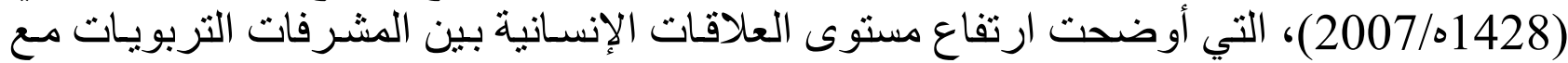

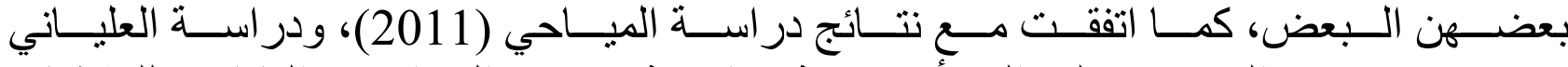

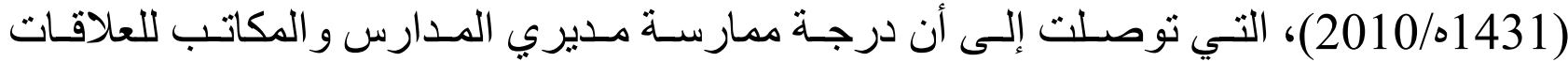
الإنسانية مع المعلمين و المشرفين بشكل عام كبيرة.

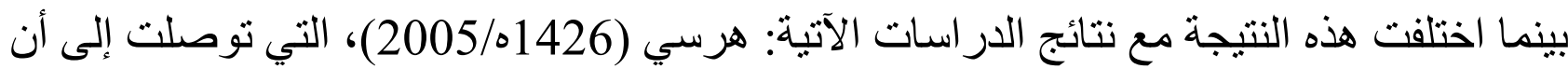

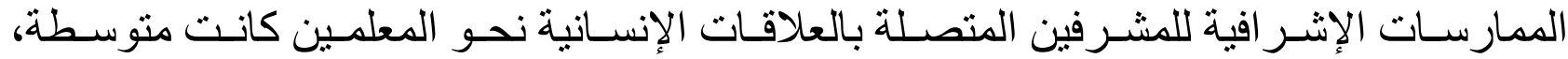

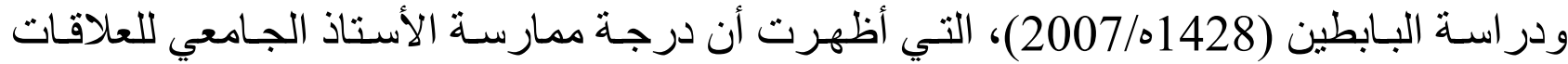

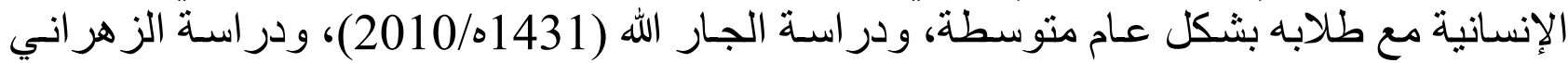
(1419ه) التي توصلت إلى أن و اقع العلاقات الإنسانية بين المشرفين و المعلمين متوسطة. مناقثة النتائج المتعلقة بالسؤال الثاني: ما مستوى اتجاهات طلبة الصف الحسادي عشر نحو مـادة

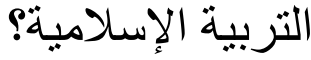

اعتمد الباحث ثنلاث مستويات في تقديره لتحليل نتائج استجابات أفر اد العينـة على مقياس الدر اسـة.

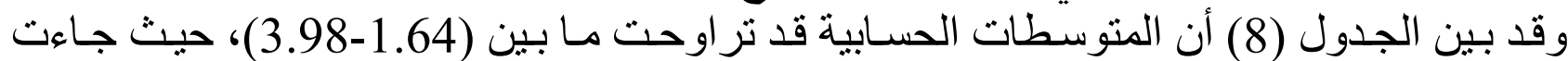

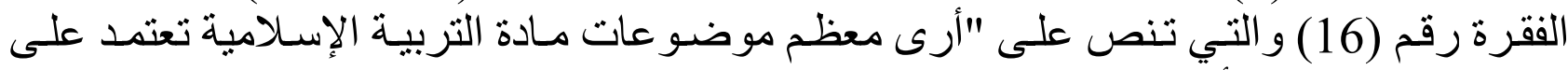

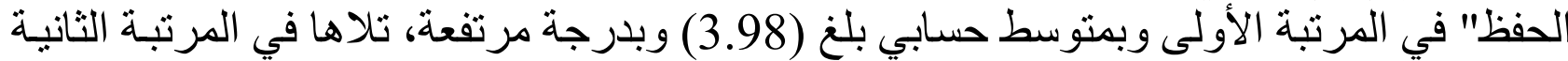

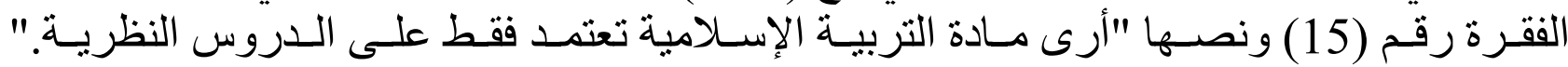


وبمتوسط حسابي بلغ (3.88) وبدرجة مرتفعة، ويعزي الباحث ذللك إلى أن مـادة التربيـة الإسـلامية

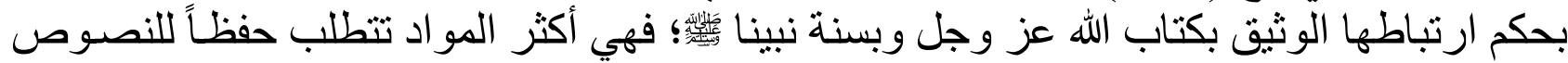

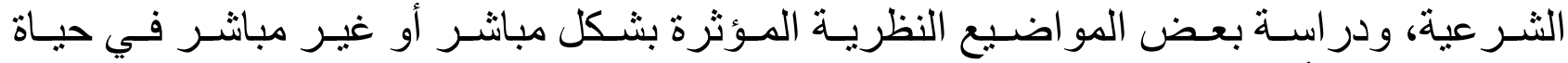

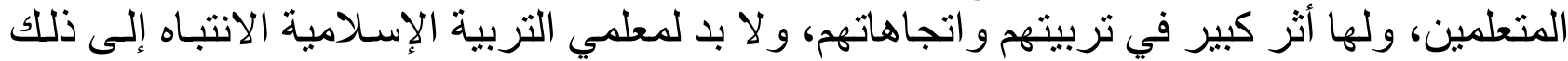

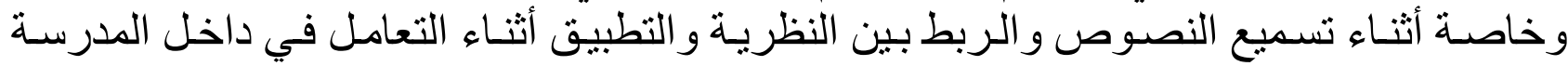
وخارجها.

تلاها في المرنبة الثالثة الفقرة رقم (8) ونصها: "تغرس مـادة التربيـة الإسـلامية في نفسي المبادئ

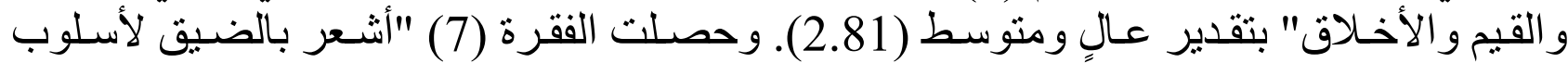

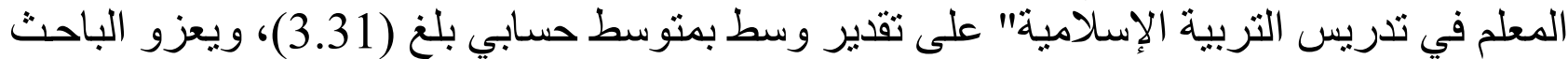

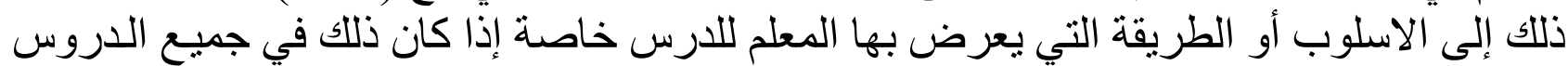

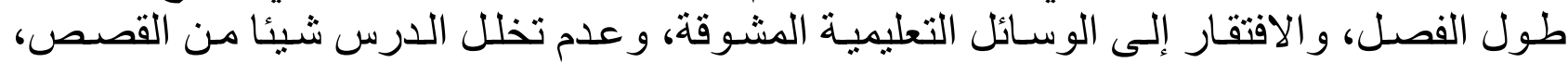

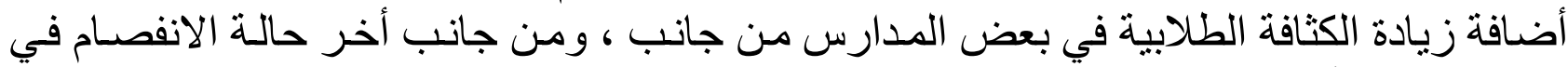

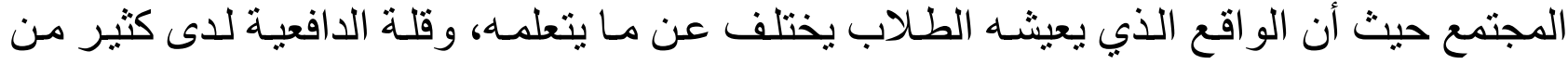

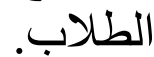

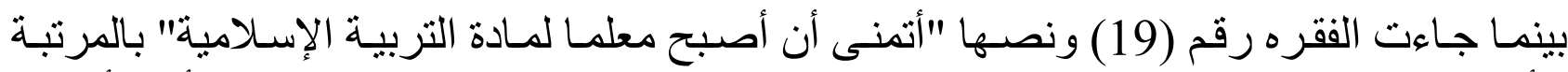

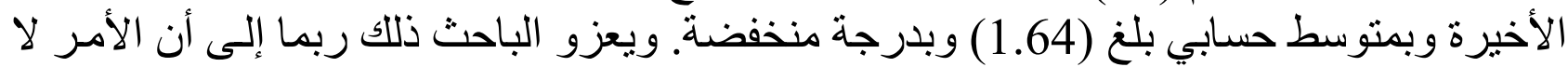

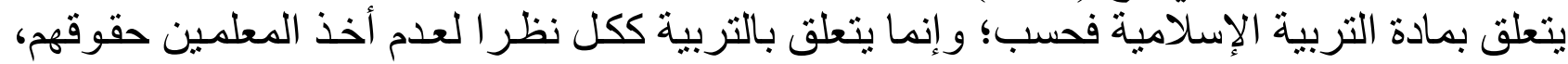

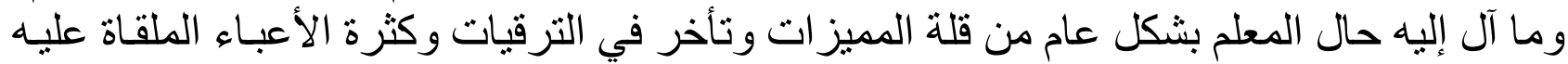

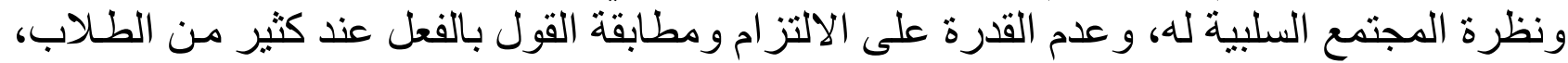

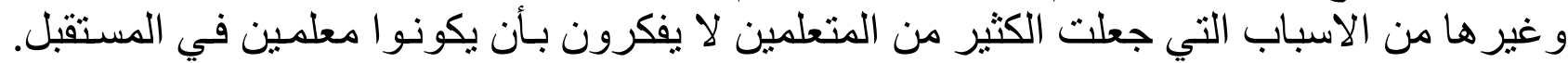

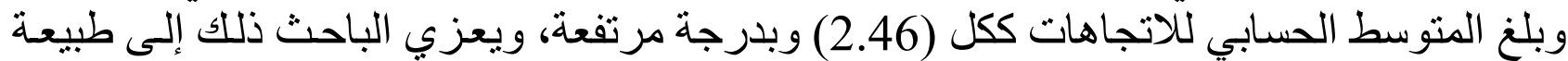

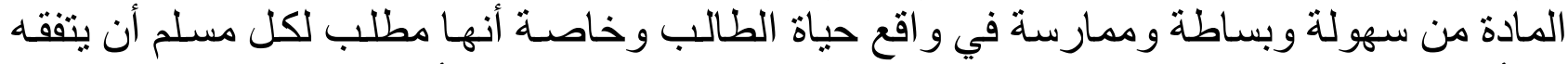

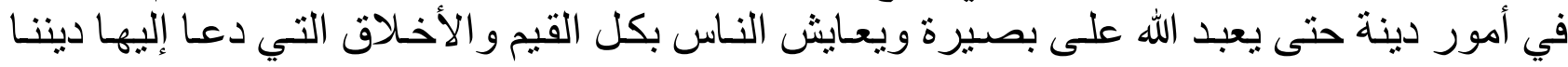
الحنيف و هذا يتطلب در اسة مادة التربية الإسلامية و التوجه إليها.

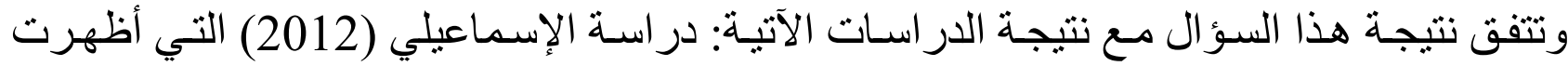

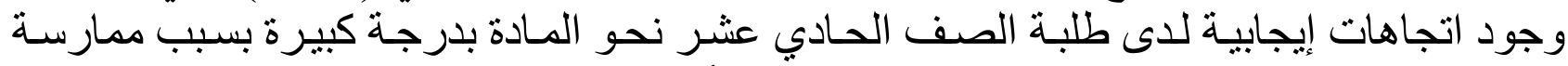

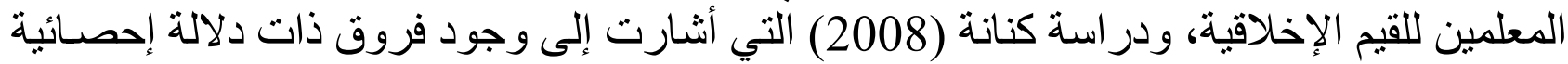

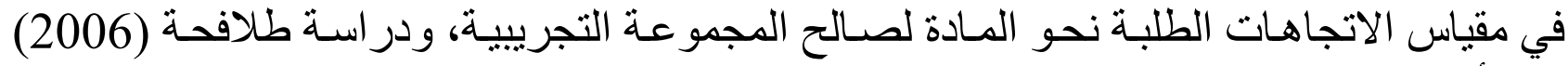

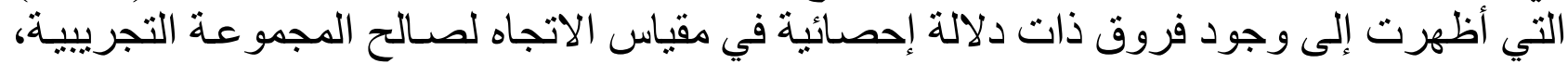

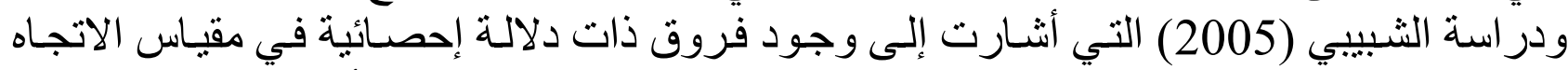

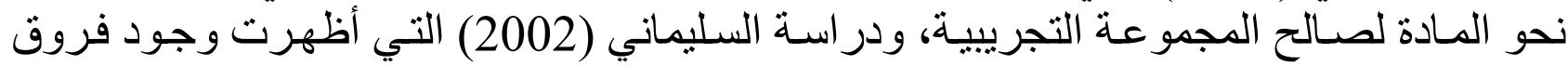

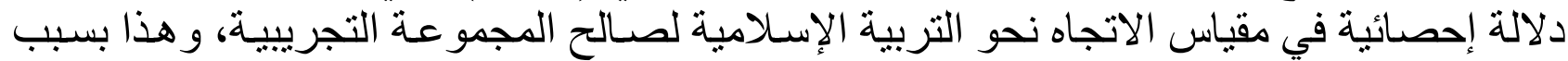
استخدام طريقة من طرق التدريس المتقدمة غير الطريقة المعتادة. توصيات الاراسة أ. التأكيد على المعلمين و التربويين على تفعيل ممارسـة العلاقات الإنسانية في العملية التعليميـة،

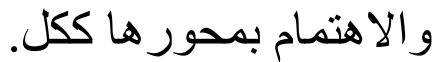


ب. تعزيز المعلمين والاداريين للاتجاهات الإيجابيـة لدى الطلبة نحو المـادة و المحافظة عليها من

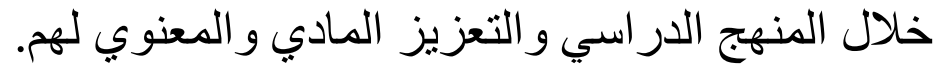

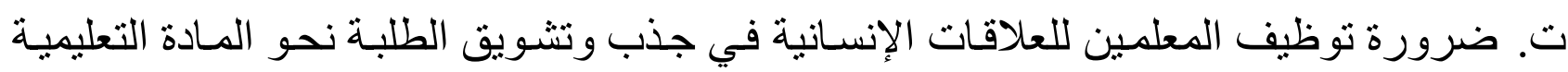
ونحو المعلم، وتغيير اتجاهاتهم بشكل إيجابي، وتعديل سلوكهر.

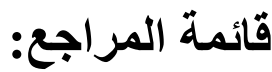

الأحمري، عبدالله مشبب. (2010). معارسة المشرفين التربوبين ومديري المعاهد العلمية للعحلاقات

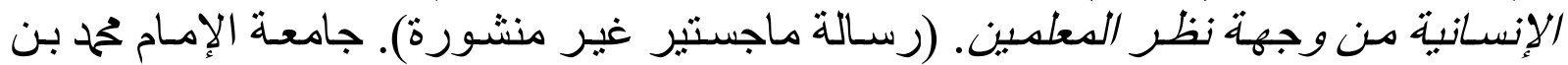
سعود، المملكة العربية السعودية.

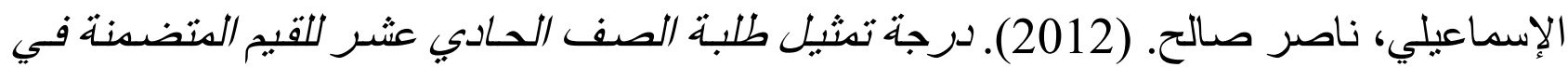

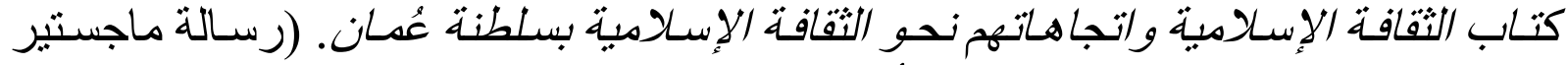
غير منشورة). جامعة مؤتنة، المملكة الأردنية الهاتشمية.

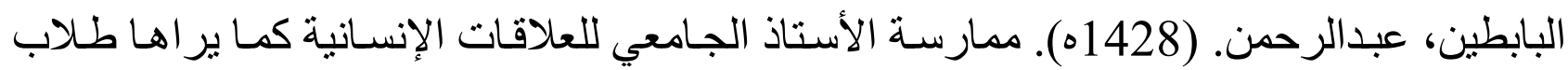

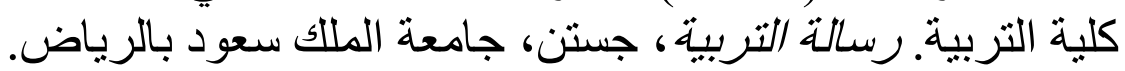

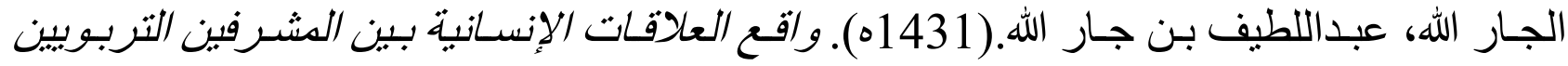

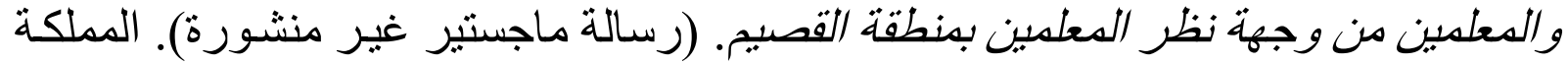

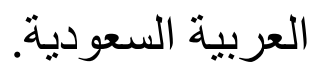

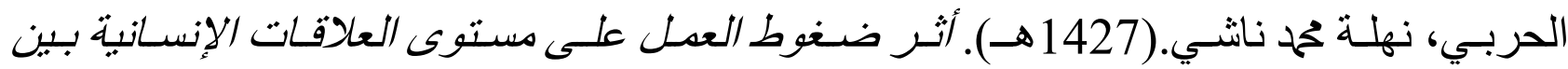

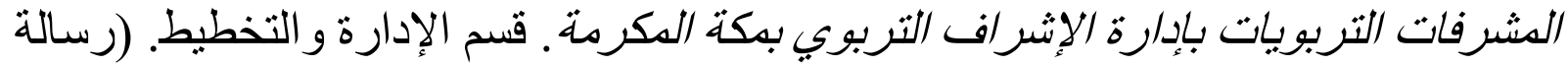

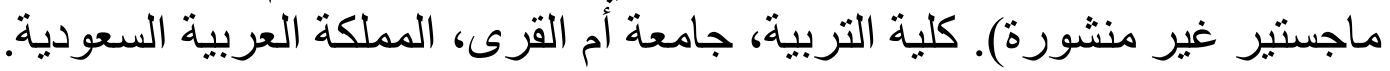

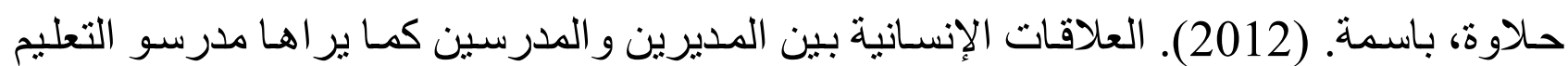

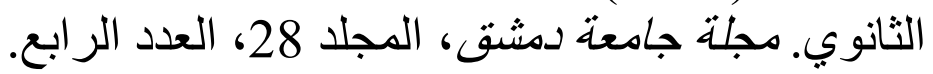

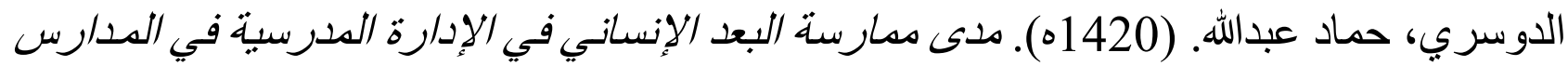

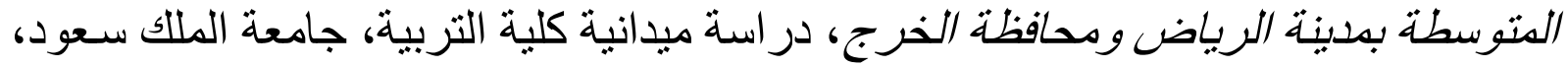
المملكة العربية السعودية.

الز غلول، عمـاد عبدالرحيم. (2003). نظريات التعلم (ط1) الأردن، عمـان: دار الثـروق للنشـر و التوزيع.

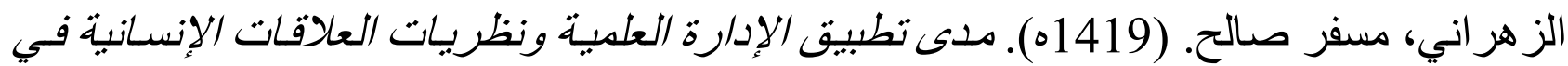

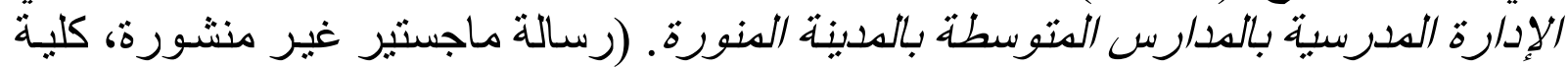

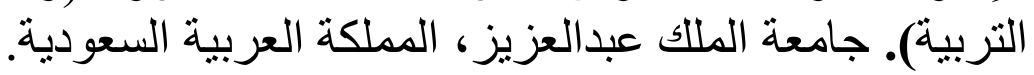

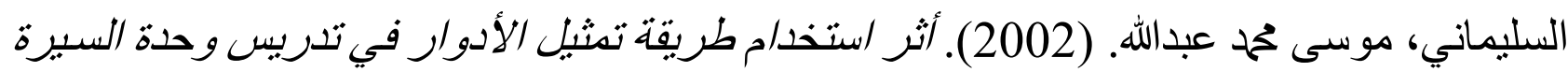

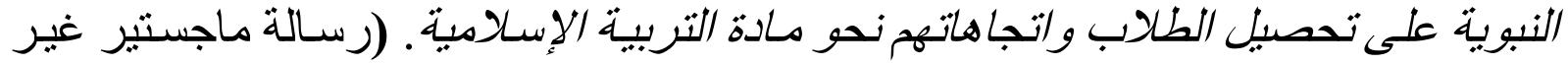
منشورة). جامعة السلطان قابوس، سلطنة عُمان. 
السو احا، منصور عبدالله. (1430ه). مدى مدارسـة المشـرفبن التربوبين للعلاقات الإنسـانبية والقبم

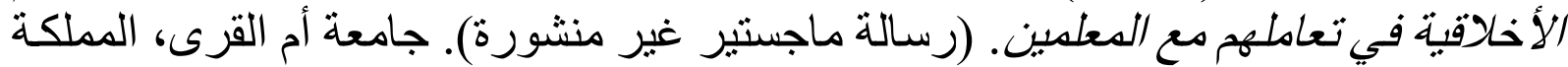
العربية السعودية.

الثـاعر، جميـل محمـود مصسطفى. (1997). القبم و الاتجاهـات كأسـاس للمنهج ( دراسـة تحلبليـة

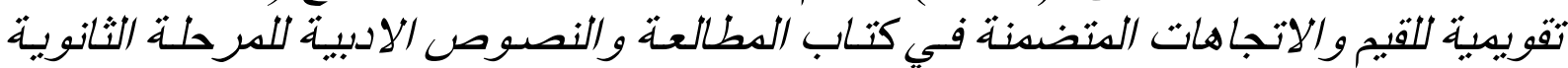
في الأردن. (رسالة ماجستير منشورة). جامعة أم درمان الإسلامية، السودان. الثبيبي، حمد صالح سالم. (2005). أثر استخدام التعليم المبرمج في تدريس التربية الإسـالامية على التى

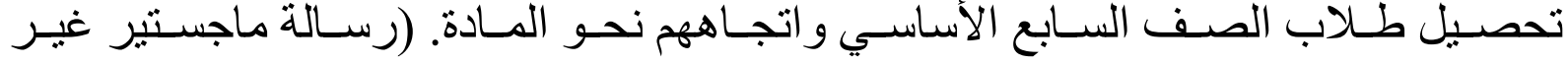
منثورة). كلية التربية، جامعة السلطان قابوس، سلطنة الطنة عُمان. الثلالدة، عوض حسين.(1401ه). العلافات الإنسانية ودورها في السلوك الإنساني، ط1، الكويت: شركة كاظمية للنشر

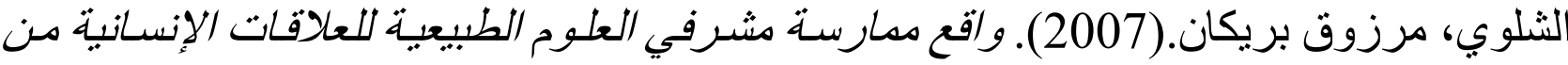

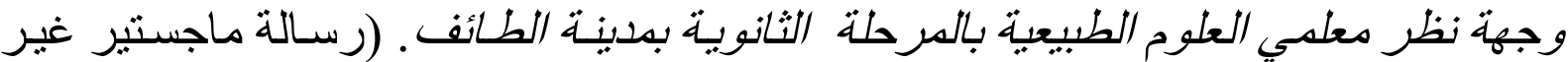
منشورة). جامعة أم القرى، المملكة العربية السعودية الهودية.

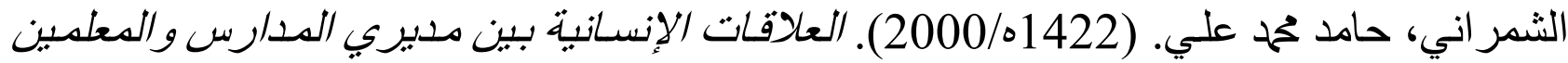

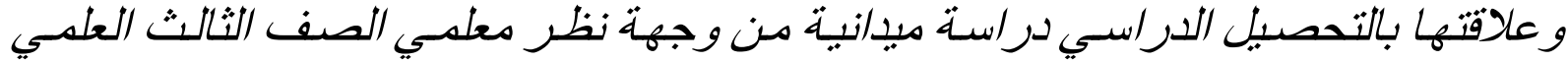

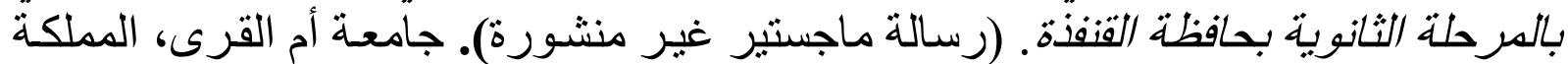
العربية السعودية. الصالح، حمح علي صالح. (1423ه). مدارسة مدير المدرسة الابتدائية للعالاقات الإنسانية كما براه

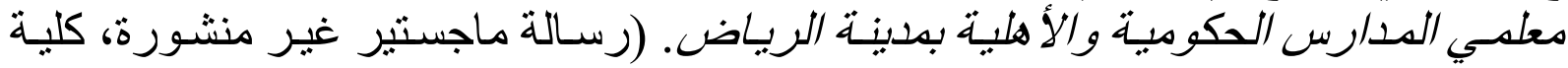

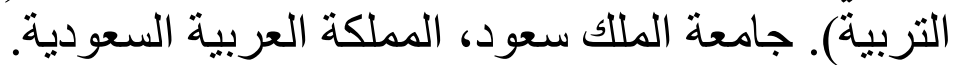
طلافحه، بركات عبدالله علي.(2006). تطوبر محتوى كتب التربية الإسـلامية للمرحلة الأساسبة المتوسطة في الأردن في ضوء منظومات من المفا هبم واختبار أثره في اتجاهـات الطلبة نحو النهو

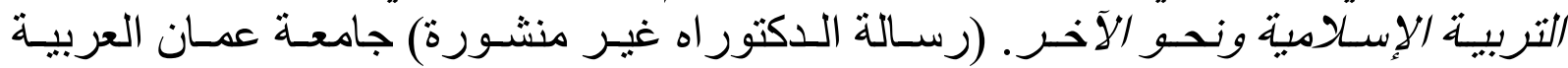
للدر استات العليا، الأردن. التهن.

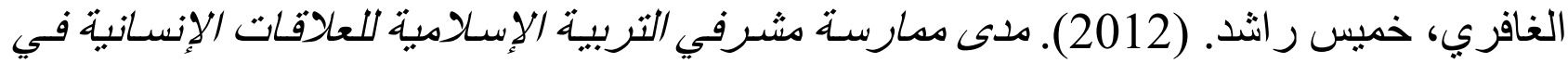

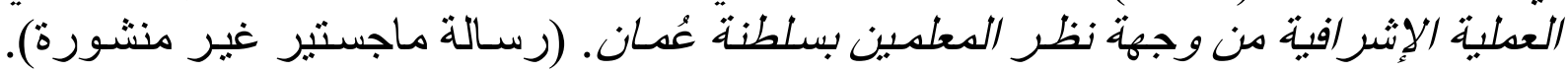
جامعة السلطان قابوس، سلطنة عُمان. كنانة، تهاني عزيز سعيد. (2008). أثر القراء/ت الإثرائبة في تحصبل طالبات الصف العاثـر في

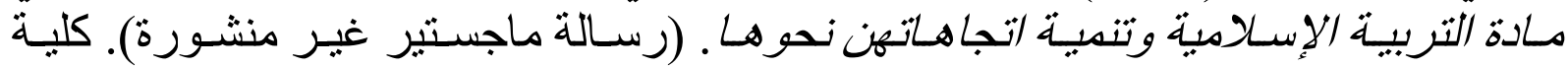
التربية، جامعة السلطان قابوس، سلطنة عُمان. ملحم، سامي حمد. (2006). سبكولوجية التعلم والتعليم. الاسس النظرية والتطبيق. (ط2) الأردن، عمان: دار المسيرة للنشر و التوزيع. المياحي، سليمان خلفان.(2011). واقع مراعاة مديري المدارس بسلطنة عُمان لدبادئ العلاقات 


$$
\begin{aligned}
& \text { الإنسـانية عند اتخاذ القرار في المواقف الإدارية. (رسـالة ماجستير غير منشورة). جامعة } \\
& \text { السلطان قابوس، سلطنة عُمان. } \\
& \text { نشو اتي، عبدالمجيد. (1986). علم النفس التربوي. عَمان : دار الفرقان. }
\end{aligned}
$$

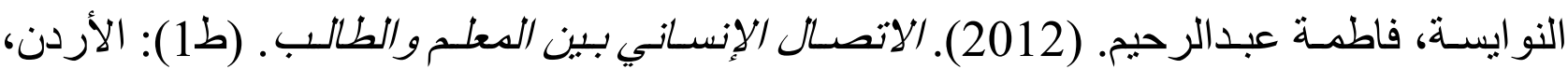

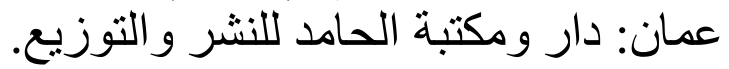

$$
\begin{aligned}
& \text { هريسي، مصطفى بن عبده جوليت.(1426ه). واقع مدارسـات المشـرفين التربوبين الموجهة نحو }
\end{aligned}
$$

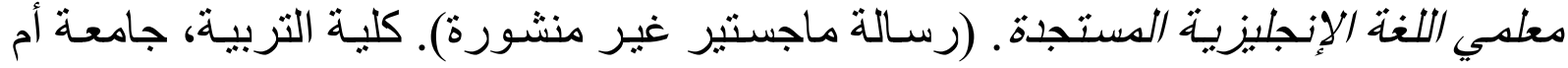

$$
\begin{aligned}
& \text { القرى، المملكة العربية السعودية. }
\end{aligned}
$$

\section{ARABIC REFERENCES IN ROMAN ALPHABETS}

Al'ahmarii, Eabdallah Mashabb. (2010). Mumarasat Almushrifin Altarbuiiyn Wamudiri Almaeahid Aleilmiat Lilealaqat Al'iinsaniat Min Wijhat Nazar Almuelimina. (Rsaalat Majstayr Ghyr Minshurta). Jamieat Al'imam Muhamad Bin Sueud, Almamlakat Alearabiat Alsaeudiat.

Al'iismaeili, Nasir Salih. (2012). Darajat Tamthil Tlbt Alsafi Alhadii Eshr Lilqiam Almutadamanat Fi Kitab Althaqafat Al'iislamiat Waitijahatihim Nahw Althaqafat Al'iislamiat Bisiltanat Eumana. (Rsalat Majstayr Ghyr Minshurta). Jamieat Mutat, Almamlakat Al'urduniyat Alhashmiat.

Albabtin, Eabdalrihmn. (1428h). Mumarasat Al'ustadh Aljamieii Lilealaqat Al'iinsaniat Kama Yaraha Tullab Kuliyat Altarbiati. Risalat Altarbiati, Jastan, Jamieat Almalik Sueud Bialriyad.

Aljar Allah, Eabdallatif Bin Jar Allaha.(1431h). Waqie Alealaqat Al'iinsaniat Bayn Almushrifin Altarbuiiyn Walmuelimin Min Wijhat Nazar Almuealimin Bimintaqat Alqasim. (Rsaalat Majstayr Ghyr Minshurta). Almamlakat Alearabiat Alsaeudiat.

Halawat, Basmat. (2012). Alealaqat Al'iinsaniat Bayn Almudirin Walmudrisin Kama Yaraha Mudrisu Altaelim Althaanawi. Majalat Jamieatan Dimashqi, Almujalid 28, Aleadad Alraabie.

Alharbi, Nuhlat Muhamad Nashi.(1427ha). 'Athar Dughut Aleamal Ealaa Mustawaa Alealaqat Al'iinsaniat Bayn Almusharifat Altarbuiaat Bi'iidarat Al'iishraf Altarbuii Bimakat Almukramati. Qism Al'iidarat Waltakhtita. (Rsaalat Majstayr Ghyr Minshurata). Kuliyat Altarbiati, Jamieat 'Am Alquraa, Almamlakat Alearabiat Alsaeudiat.

Alduwsri, Hammad Eibdalluh. (1420h). Madaa Mumarasat Albued Al'iinsanii Fi Al'iidarat Almadrasiat Fi Almadaris Almutawasitat Bimadinat Alriyad Wamuhafazat Alkhurji, Dirasat Maydaniat Kuliyat Altarbiati, Jamieat Almalik Sueuad, Almamlakat Alearabiat Alsaeudiat.

Alzaghlul, Eimad Eibdalrhim. (2003). Nazrayat Altaelim (T1) Al'urdun, Eamana: Dar Alshuruq Lilnashr Waltawzie.

Alzahraniu, Masafir Salih. (1419h). Madaa Tatbiq Al'iidarat Aleilmiat Wanazariaat Alealaqat Al'iinsaniat Fi Al'iidarat Almadrasiat Bialmadaris Almutawasitat Bialmadinat Almunawrati. (Rsaalat Majstayr Ghyr Manshurati, Kuliyat Altarbi). Jamieat Almalik Eibdaleziz, Almamlakat Alearabiat Alsaeudiat.

Alsulaymaniu, Musaa Muhamad Eabdalluh. (2002). 'Athar Aistikhdam Tariqat Tamthil Al'adwar Fi Tadris Wahdat Alsiyrat Alnabawiat Ealaa Tahsil Altullab Waitijahatihim Nahw Madat Altarbiat Al'iislamiati. (Rsaalat Majstayr Ghyr Minshurta). Jamieat Alsultan Qabaws, Saltanat Oman.

Alsawaha, Mansur Eibdalluh. (1430h). Madaa Mumarasat Almushrifin Alturbuiiyn Lilealaqat Al'iinsaniat Walqim Al'akhlaqiat Fi Taeamulihim Mae Almuelmin. (Rsalat Majstayr Ghyr Minshurta). Jamieat 'Am Alquraa, Almamlakat Alearabiat Alsaeudiat.

Alshaaeiru, Jamil Mahmud Mustafaa. (1997). Alqiam Walaitijahat Ka'asas Lilmunhaj ( Dirasatan Tahliliat Taqwimiatan Lilqiam Walaitijahat Almutadamanat Fi Kitab Almutalaeat Walnusus Aladibiat Lilmarhalat Alththanawiat Fi Al'urdunn. (Rsaalat Majstir Munshurta). Jamieat 'Am Darman Al'iislamiat, Alsuwdan.

Alshabibii, Muhamad Salih Salim. (2005). 'Athar Aistikhdam Altaelim Almubarmij Fi Tadris Altarbiat Al'iislamiat Ealaa Tahsil Tullab Alsafi Alssabie Al'asasii Waitijahihim Nahw Almadata. (Rsaalat Majstayr Ghyr Minshurata). Kuliyat Altarbiati, Jamieat Alsultan Qabus, Saltanat Oman. 
Alshalalidat, Eiwad Husayna.(1401h). Alealaqat Al'iinsaniat Wadawruha Fi Alsuluk Al'iinsani, Ta1, Alkawayta: Sharikat Kazmiat Lilnashrr.

Alshalwi, Marzuq Bariukan.(2007). Waqie Mumarasat Musharifi Aleulum Altabieiat Lilealaqat Al'iinsaniat Min Wijhat Nazar Muelimi Aleulum Altabieiat Bialmarhalat Alththanawiat Bimadinat Altayif. (Rsaalat Majstayr Ghyr Minshurta). Jamieat 'Am Alquraa, Almamlakat Alearabiat Alsaeudiat.

Alshumarani, Hamid Muhamad Eali. (1422h/2000). Alealaqat Al'iinsaniat Bayn Mudiri Almadaris Walmuelimin Waealaqatiha Bialtahsil Aldirasii Dirasat Maydaniat Min Wijhat Nazar Muelimii Alsaf Alththalith Aleilmia Bialmarhalat Alththanawiat Bihafizat Alqanfadhati. (Rsaalat Majstayr Ghyr Minshurta). Jamieat 'Am Alquraa, Almamlakat Alearabiat Alsaeudiat.

Alsaalihu, Muhamad Eali Salih. (1423h). Mumarasat Mudir Almadrasat Alaibtidayiyat Lilealaqat Al'iinsaniat Kama Yarah Muelimiu Almadaris Alhukumiat Wal'ahliat Bimadinat Alriyad. (Rsalat Majstayr Ghyr Manshurati, Kuliyat Altarby). Jamieat Almalik Sueuad, Almamlakat Alearabiat Alsaeudiat.

Talafihuhu, Barakat Ebdallah Ealy.(2006). Tatwir Muhtawaa Kutib Altarbiat Al'iislamiat Lilmarhalat Al'asasiat Almutawasitat Fi Al'urduni Fi Daw' Manzumat Min Almafahim Waikhtibar 'Atharah Fi Aitijahat Altalabat Nahw Altarbiat Al'iislamiat Wanahw Alakhara. (Rsaalat Aldukturah Ghyr Mnshur) Jamieat Eamman Alearabiat Lildirasat Aleulya, Al'urdunn.

Alghafri, Khamis Rashid. (2012). Madaa Mumarasat Mushrifi Altarbiat Al'iislamiat Lilealaqat Al'iinsaniat Fi Aleamaliat Al'iishrafiat Min Wijhat Nazar Almuealimin Bisiltanat Eumaana. (Rsalat Majstayr Ghyr Minshurta). Jamieat Alsultan Qabus, Saltanat Oman.

Kananat, Tihani Eaziz Sueyd. (2008). 'Athar Alqara'at Al'iithrayiyat Fi Tahsil Talibat Alsafi Aleashir Fi Madat Altarbiat Al'iislamiat Watanmiat Aitijahatihin Nahwha. (Rsalat Majstayr Ghyr Minshurata). Kuliyat Altarbiati, Jamieat Alsultan Qabus, Saltanat Oman.

Mulhim, Sami Muhmd. (2006). Saykulujiat Altaelum Waltaelima: Al'usus Alnazariat Waltatbiq. (T2) Al'urdunu, Eamana: Dar Almasirat Lilnashr Waltawzie.

Almiahi, Sulayman Khilfan.(2011). Waqie Muraeat Mudiri Almadaris Bisiltanat Eamman Limabadi Alealaqat Al'iinsaniat Eind Aitikhadh Alqarar Fi Almawaqif Al'iidariati. (Rsaalat Majstayr Ghyr Minshurta). Jamieat Alsultan Qabus, Saltanat Oman.

Nashawati, Eibdalmjida. (1986). Eilm Alnafs Altarbawi. Eaman : Dar Alfurqan.

Alnawaysat, Fatimat Eabdalrhim. (2012). Alaitisal Al'iinsaniu Bayn Almaelam Waltaalib. (T1): Al'urdunu, Eaman: Dar Wamuktabat Alhamid Lilnashr Waltawzie.

Harisi, Mustafaa Bin Eabdah Julyt.(1426h). Waqie Mumarasat Almushrifin Altarbuiiyn Almuajahat Nahw Muelimi Allughat Al'iinjliziat Almustajdati. (Rsaalat Majstayr Ghyr Minshurata). Kuliyat Altarbiati, Jamieat 'Am Alquraa, Almamlakat Alearabiat Alsaeudiat. 